\title{
Reconstruction of Northern Hemisphere 1950-2010 atmospheric non-methane hydrocarbons
}

\author{
D. Helmig ${ }^{1}$, V. Petrenko ${ }^{1,2}$, P. Martinerie ${ }^{3}$, E. Witrant ${ }^{4}$, T. Röckmann ${ }^{5}$, A. Zuiderweg ${ }^{5}$, R. Holzinger ${ }^{5}$, J. Hueber ${ }^{1}$, \\ C. Thompson ${ }^{1}$, J. W. C. White $^{1}$, W. Sturges ${ }^{6}$, A. Baker ${ }^{7}$, T. Blunier ${ }^{8}$, D. Etheridge ${ }^{9}$, M. Rubino ${ }^{9}$, and P. Tans ${ }^{10}$ \\ ${ }^{1}$ Institute of Arctic and Alpine Research, University of Colorado, Boulder, USA \\ ${ }^{2}$ Department of Earth and Environmental Sciences, University of Rochester, Rochester, USA \\ ${ }^{3}$ UJF-Grenoble/CNRS, Laboratory for Glaciology and Geophysics of the Environment, Grenoble, France \\ ${ }^{4}$ UJF-Grenoble/CNRS, Grenoble Image Parole Signal Automatique, St. Martin d'Hères, France \\ ${ }^{5}$ Institute for Marine and Atmospheric Research Utrecht, Utrecht University, the Netherlands \\ ${ }^{6}$ School of Environmental Sciences, University of East Anglia, Norwich, UK \\ ${ }^{7}$ Max Planck Institute for Chemistry, Mainz, Germany \\ ${ }^{8}$ Niels Bohr Institute, University of Copenhagen, Denmark \\ ${ }^{9}$ Centre for Australian Weather and Climate Research, CSIRO Marine and Atmospheric Research, Aspendale, Australia \\ ${ }^{10}$ Global Monitoring Division, Earth Systems Research Laboratory, NOAA, Boulder, USA
}

Correspondence to: D. Helmig (detlev.helmig@ colorado.edu)

Received: 1 April 2013 - Published in Atmos. Chem. Phys. Discuss.: 15 May 2013

Revised: 26 November 2013 - Accepted: 9 December 2013 - Published: 10 February 2014

\begin{abstract}
The short-chain non-methane hydrocarbons (NMHC) are mostly emitted into the atmosphere by anthropogenic processes. Recent studies have pointed out a tight linkage between the atmospheric mole fractions of the NMHC ethane and the atmospheric growth rate of methane. Consequently, atmospheric NMHC are valuable indicators for tracking changes in anthropogenic emissions, photochemical ozone production, and greenhouse gases. This study investigates the 1950-2010 Northern Hemisphere atmospheric $\mathrm{C}_{2}-\mathrm{C}_{5} \mathrm{NMHC}$ ethane, propane, $i$-butane, $n$ butane, $i$-pentane, and $n$-pentane by (a) reconstructing atmospheric mole fractions of these trace gases using firn air extracted from three boreholes in 2008 and 2009 at the North Greenland Eemian Ice Drilling (NEEM) site and applying state-of-the-art models of trace gas transport in firn, and by (b) considering eight years of ambient NMHC monitoring data from five Arctic sites within the NOAA Global Monitoring Division (GMD) Cooperative Air Sampling Network. Results indicate that these NMHC increased by $\sim 40$ $120 \%$ after 1950, peaked around 1980 (with the exception of ethane, which peaked approximately $10 \mathrm{yr}$ earlier), and have since dramatically decreased to be now back close to 1950 levels. The earlier peak time of ethane vs. the $C_{3}-C_{5}$
\end{abstract}

NMHC suggests that different processes and emissions mitigation measures contributed to the decline in these NMHC. The $60 \mathrm{yr}$ record also illustrates notable increases in the ratios of the isomeric iso- $/ n$-butane and $i s o-/ n$-pentane ratios. Comparison of the reconstructed NMHC histories with 1950 2000 volatile organic compounds (VOC) emissions data and with other recently published ethane trend analyses from ambient air Pacific transect data showed (a) better agreement with North America and Western Europe emissions than with total Northern Hemisphere emissions data, and (b) better agreement with other Greenland firn air data NMHC history reconstructions than with the Pacific region trends. These analyses emphasize that for NMHC, having atmospheric lifetimes on the order of $<2$ months, the Greenland firn air records are primarily a representation of Western Europe and North America emission histories.

\section{Introduction}

The primary sources of short-chain non-methane hydrocarbons (NMHC) released into the atmosphere are anthropogenic processes that are linked to the extraction of 
petroleum from geological reservoirs, the distillation and distribution of oil and gas products, and incomplete combustion of fossil fuel (Pozzer et al., 2010). For ethane, the lightest NMHC, anthropogenic sources constitute approximately $75 \%$ of global emissions; this fraction increases to $98 \%$ for the butanes and pentanes. NMHC are also by-products of biomass burning; however, biomass burning associated emissions make up a relatively small fraction of the short-chain alkanes on a global scale, estimated at up to $22 \%$ and $7 \%$ for ethane and propane, respectively (Pozzer et al., 2010). Another study found that natural degassing through geologic seeps could contribute significantly to the global budget of ethane and propane (Etiope and Ciccioli, 2009). In their analyses of 238 observations of surface gas seepage, the authors concluded that up to $17 \%$ of ethane released into the atmosphere is the result of geologic microseepage.

In the atmosphere, NMHC are oxidized primarily by the OH radical (Parrish et al., 1992), with rate constants increasing with molecule size. Resulting NMHC atmospheric lifetimes range from a few days (for the $\mathrm{C}_{5} \mathrm{NMHC}$ ) to a few months (ethane). NMHC removal rates vary by season and latitude, resulting in seasonal cycles that are of opposite phase in the Northern and Southern Hemispheres (Montzka et al., 2000). Due to the preponderance of anthropogenic NMHC sources in the Northern Hemisphere, NMHC atmospheric mole fractions exhibit a strong latitudinal gradient with the highest atmospheric mole fractions observed in the Arctic, where atmospheric removal rates are relatively low, and lower levels near the Equator and in the Southern Hemisphere (Ehhalt et al., 1985; Singh et al., 1988).

Peroxy radicals formed in the course of NMHC oxidation can contribute to ozone production both on local and regional scales (Sillman et al., 1990; Kleinman et al., 1995; Carpenter et al., 1997). Consequently, NMHC emissions are of concern for air quality and radiative forcing. A number of recent studies have investigated atmospheric concentration trends of NMHC species, with the objective of using such observations for deciphering emission changes and the effectiveness of volatile organic compound (VOC) emission controls that have been implemented in most industrialized nations during the past several decades (e.g., Gautrois et al., 2003; Aydin et al., 2011; Simpson et al., 2012). There is little information on the pre-industrial atmospheric NMHC burden, as retrievals from ice cores have been hampered by analytical problems (Aydin et al., 2007). Long-term atmospheric monitoring programs and comparisons of earlier ambient records with newer data have indicated a decline in atmospheric ethane in recent years (Simpson et al., 2012). This tendency was confirmed by two recent firn air studies that sampled air in boreholes from two sites (Summit and North Greenland Ice Core Project NGRIP) on the central Greenland ice sheet (Aydin et al., 2011; Worton et al., 2012). Both studies show increases in ethane in the first part of the record, a flattening out of the growth rate in the late 1970s, and the onset of a decline thereafter, although the extent of the inferred decline differs. Further evidence linking declining atmospheric NMHC background levels to anthropogenic emissions stems from urban region data sets. For instance, comparisons of long-term monitoring data from London and Los Angeles have shown significant declines in NMHC ranging from 3-12\% per year (von Schneidemesser et al., 2010; Warneke et al., 2012) during the last $\sim 5$ decades. Declining NMHC mole fractions have also been noted in rural environments, such as at Hohenpeissenberg, a semi-rural site in Southern Germany close to Munich, however, at somewhat lower rates than in inner cities (von Schneidemesser et al., 2010).

Recent comparisons of ethane ambient air mole fractions from a Pacific transect with the growth rate of methane (Simpson et al., 2012) have shown a tight coupling between these two variables. Decadal trends in ethane have therefore been used to estimate the contribution of anthropogenic emission changes to the observed slowdown of the methane atmospheric growth rate during the late 1990s and first decade of the 21st century (Aydin et al., 2011; Simpson et al., 2012).

In this work we investigate, besides ethane, five additional NMHC, i.e., propane, $i$-butane, $n$-butane, $i$-pentane, and $n$ pentane (see Table 1 for physical properties), in firn air samples withdrawn from three boreholes at the North Greenland Eemian Ice Drilling (NEEM) site. These data are used to reconstruct year $\sim 1950-2010$ atmospheric histories of these compounds. Recent records from regular ambient air sampling at five Arctic locations are used to further evaluate the results of the firn air modeling by comparison of modeled NMHC trends and ratios with the more recent ambient record.

\section{Experimental}

\subsection{Firn air sampling}

Air was extracted from firn boreholes near the NEEM deep ice core site in Northern Greenland. Two boreholes, located at $77.43^{\circ} \mathrm{N}, 51.10^{\circ} \mathrm{W}, 2484 \mathrm{~m}$ a.s.l., and separated by $64 \mathrm{~m}$ were sampled in July 2008. One of these was sampled with a firn air system from the University of Bern (Schwander et al., 1993) and is referred to as "2008 EU hole". The other borehole was sampled with a firn air system from the US (Battle et al., 1996) and is referred to as "2008 US hole". The US hole was sampled to a depth of $75.6 \mathrm{~m}$; the EU hole was sampled to a depth of $77.8 \mathrm{~m}$. More details on sampling procedure and other measurements on air from these two boreholes can be found in Buizert et al. (2012). Further firn air sampling took place during July 2009 from a borehole located $\sim 250 \mathrm{~m}$ away from the 2008 boreholes (Zuiderweg et al., 2013). This borehole was sampled to a depth of $76.0 \mathrm{~m}$ with a firn air device from CSIRO and is referred to as "2009 hole". Sampling system blanks and analyte recoveries were 
Table 1. NMHC included in this study with pertinent physical variables.

\begin{tabular}{lcccc}
\hline $\begin{array}{l}\text { Compound } \\
\text { Name }\end{array}$ & $\begin{array}{c}\text { Molecular } \\
\text { Formula }\end{array}$ & $\begin{array}{c}\text { Molecular } \\
\text { Mass } \\
\left(\mathrm{g} \mathrm{mol}^{-1}\right)\end{array}$ & $\begin{array}{c}\text { Approximate Atmospheric } \\
\text { Lifetime at } 24 \mathrm{~h}[\mathrm{OH}]= \\
6.5 \times 10^{5} \text { molecules cm } \\
\text { (days) }\end{array}$ & $\begin{array}{c}\text { Relative } \\
\text { Diffusion } \\
\text { Coefficient } \\
\mathrm{D}^{-3} \mathrm{D}_{\mathrm{CO}_{2}}\end{array}$ \\
\hline Ethane & $\mathrm{C}_{2} \mathrm{H}_{6}$ & 30.1 & 66 & 0.905 \\
Propane & $\mathrm{C}_{3} \mathrm{H}_{8}$ & 44.1 & 15 & 0.702 \\
$i$-Butane & $\mathrm{C}_{4} \mathrm{H}_{10}$ & 58.1 & 7.6 & 0.583 \\
$n$-Butane & $\mathrm{C}_{4} \mathrm{H}_{10}$ & 58.1 & 7.0 & 0.584 \\
$i$-Pentane & $\mathrm{C}_{5} \mathrm{H}_{12}$ & 72.2 & 4.6 & 0.511 \\
$n$-Pentane & $\mathrm{C}_{5} \mathrm{H}_{12}$ & 72.2 & 4.5 & 0.544 \\
\hline
\end{tabular}

tested for the 2008 EU and US firn air sampling systems. A cylinder of ultra-zero air, containing low (below typical ambient) mixing ratios of the NMHC was used on site at NEEM to either directly fill the sampling flasks or to fill them via the firn air device, by connecting the gas cylinder to the firn air device intake line. Flask flushing and filling procedure for these tests mimicked normal sample collection, except consideration of possible leaking and outgassing from the bladder.

\subsection{NMHC analyses}

Air extracted from the three boreholes was sampled and subsequently analyzed by three different laboratories.

\subsubsection{INSTAAR}

For the 2008 US and 2008 EU holes air was sampled into $2.5 \mathrm{~L}$ glass flasks. Analysis of these samples was performed at the Institute of Arctic and Alpine Research (INSTAAR) at the University of Colorado, Boulder, USA. 0.5 L of air was extracted from the flasks, dried to a dewpoint of $-30{ }^{\circ} \mathrm{C}$, and $\mathrm{NMHC}$ were then preconcentrated on a Peltier-cooled microadsorbent trap. After thermal desorption, NMHC were separated on an $\mathrm{Al}_{2} \mathrm{O}_{3}$ porous layer open tubular (PLOT) column by temperature-programmed gas chromatography (GC) with flame ionization detection (FID). The GC was calibrated by analyzing a series of gravimetrically prepared synthetic and whole air standards. The INSTAAR lab was audited by the World Calibration Center (WCC) for Volatile Organic Compounds (VOC) in 2009 and 2011 and found to meet all quality criteria set by the World Meteorological Organization (WMO) Global Atmospheric Watch (GAW) program for VOC.

\subsubsection{IMAU}

Samples drawn from the 2009 hole were pumped directly into Luxfer (Nottingham, United Kingdom) 5 L stainless steel flasks, pressurized to 120 bar. The contents of each of the sample flasks were measured twice, on different days at the stable isotope laboratory of the Institute for Marine and Atmospheric Research Utrecht (IMAU), Netherlands. The measurement system used is described in Zuiderweg et al. (2011). This instrument features a novel method of removing unwanted compounds that would otherwise interfere with analysis (e.g., $\mathrm{CO}_{2}$ and $\mathrm{CH}_{4}$ ) by use of a $3 \mathrm{~m} \times 6.35 \mathrm{~mm}$ Porapak Q column. Subsequent peak separation of compounds prior to mass spectrometry detection (HP 5970 quadrupole MS) was accomplished with a $52.5 \mathrm{~m} \times 0.25 \mathrm{~mm}$ Poraplot Q column. The calibration scale was established by prefocusing distinct volumes of two reference gases: a 5-compound (ethane, propane, methyl chloride, benzene and toluene) NMHC working standard with mole fractions of 100 to $200 \mathrm{nmol} \mathrm{mol}^{-1} \pm 5 \%$, and a 9-compound gas standard with a mix of $\mathrm{C}_{2}$ to $\mathrm{C}_{5}$ alkanes, alkenes and alkynes with mole fractions ranging from $30-50 \mathrm{nmol} \mathrm{mol}^{-1} \pm 5 \%$. Measurement precision was determined to be $\pm 5 \%$. Routine calibration of the instrument was accomplished by measuring the NMHC standard before the start and after the finish of the daily measurement series. Blank measurements showed no remnant compounds or interfering peaks (Zuiderweg et al., 2012).

\subsubsection{Max Plank Iinstitute/University of East Anglia}

Samples were collected into 3.0 L stainless steel canisters and analyzed at the Max Planck Institute for Chemistry (MPIC) in Mainz, Germany. For each flask a 1L (STP) aliquot of sample was pretreated by drying with magnesium perchlorate $\left(\mathrm{Mg}\left(\mathrm{ClO}_{4}\right)_{2}\right)$ followed by cryogenic preconcentration on a Carbopack adsorbent trap. The sample was then thermally desorbed, cryofocused on a $1.75 \mathrm{~m}$ loop wall coated open tubular (WCOT) column and then introduced to the GC, where components were separated on a Petrocol DH capillary column and detected using an FID. Calibration was based on individual compound response factors determined from analysis of a gravimetrically prepared synthetic mixture of NMHC (accuracy of $\pm 2 \%$ ) purchased from the National Physical Laboratory (NPL, United Kingdom) and whole air standards. Analytical precision errors are compound dependent, and are less than $2 \%$ for the $\mathrm{C}_{2}-\mathrm{C}_{6}$ alkanes. The MPIC lab was audited in 2009 by the World 
Calibration Center for VOCs and found to meet the quality guidelines set by the WMO-GAW VOC program. This is the same analytical system used to analyze samples collected aboard the Civil Aircraft for the Regular Investigation of the atmosphere Based on an Instrument Container (CARIBIC) flying observatory; a more detailed description of the project and analyses can be found in Baker et al. (2010).

\subsubsection{NOAA/INSTAAR Flask Network Analyses}

Since 2004 NOAA and INSTAAR have been operating a global VOC monitoring program building on the NOAA Global Cooperative Air Sampling Network. VOC are quantified in pairs of glass flasks that are collected weekly to biweekly at 44 global background monitoring sites. These samples are analyzed on the same system as used for the NEEM firn air flasks. More analytical and program details are provided by Pollmann et al. (2008) and at http://instaar.colorado. edu/arl/Global_VOC.html. In this paper data from Alert, $82.5^{\circ} \mathrm{N}, 62.32^{\circ} \mathrm{W}, 200 \mathrm{~m}$ a.s.1., Nunavut, Canada; Barrow, $71.32^{\circ} \mathrm{N}, 156.60^{\circ} \mathrm{W}, 11 \mathrm{~m}$ a.s.l., Alaska, USA; Ny-Ålesund, $78.90^{\circ} \mathrm{N}, 11.88^{\circ} \mathrm{E}, 475 \mathrm{~m}$ a.s.l., Svalbard, Spitzbergen, Norway; Pallas $67.97^{\circ} \mathrm{N}, 24.12^{\circ} \mathrm{E}, 560 \mathrm{~m}$ a.s.l., Finland; Stohofdyi, Vestmannaeyjar, $63.33^{\circ} \mathrm{N}, 20.29^{\circ} \mathrm{W}, 118 \mathrm{~m}$ a.s.l., Iceland, and Summit, $72.57^{\circ} \mathrm{N}, 38.48^{\circ} \mathrm{W}, 3238 \mathrm{~m}$ a.s.l., Greenland; are used in conjunction with the firn air results (Fig. 1). Glass flask samples from these Arctic sites are typically analyzed 3-9 months after sample collection, and after the flasks have undergone prior analysis for other greenhouse gases on three other instruments.

\subsubsection{INSTAAR in situ analyses}

From summer 2008-2010 continuous in situ analyses of $\mathrm{C}_{2}-$ $\mathrm{C}_{7} \mathrm{NMHC}$ were conducted at Summit with a fully automated and remotely controlled GC/FID instrument, using a similar method and instrument components as described in Tanner et al. (2006). On average six samples were analyzed daily. Calibrations and blank runs were conducted every 1-2 days. Calibration standards were cross-calibrated against the laboratory calibration scale for the network flask program described above.

\subsection{Data quality control and filtering}

Figure 2 shows firn air NMHC measurements from all boreholes and laboratories after removal of data that were clearly influenced by analytical problems during measurement. While the different boreholes and data reported from the three laboratories agreed on the main features of the depth mole fraction profiles, some samples appeared to be affected by contamination. Because the number of available data points at any given depth level in a single borehole is small, the different data sets were combined to allow for better statistics for outlier testing. This approach is well justified for the $2008 \mathrm{EU}$ borehole, as the INSTAAR and MPI-UEA

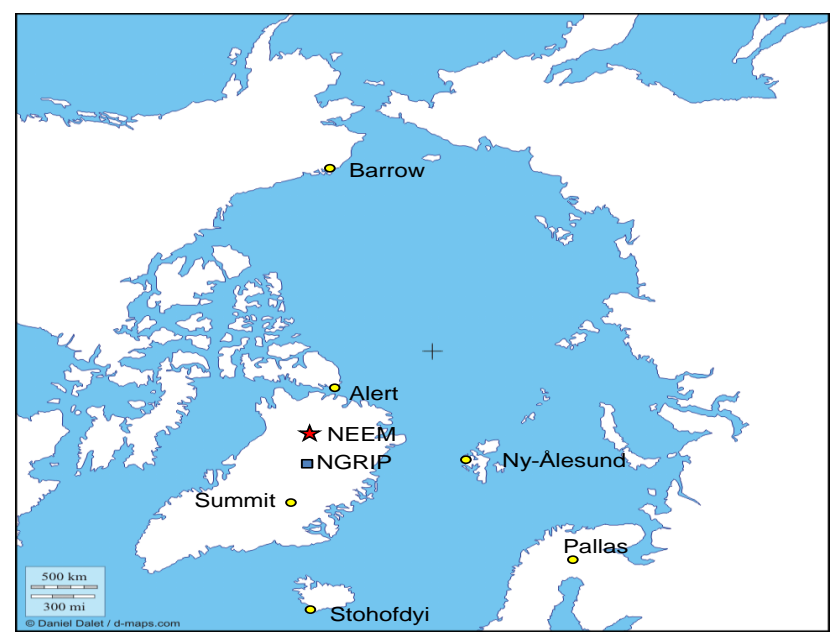

Fig. 1. Map of the Arctic Region showing the locations of the NEEM and NGRIP drilling sites and of the ambient monitoring sites used for comparison in reference to the NEEM data.

data sets can be placed on the same calibration scale given that both laboratories were audited and found to meet the data quality criteria of the WCC.

The differences in gas age distributions between the 2008 EU and US boreholes are relatively small (Buizert et al., 2012) and are not expected to result in significant differences in NMHC mole fraction profiles with depth. Data from the 2008 US borehole were thus used to help test four suspected outliers from the 2008 EU borehole. The NMHC depth profiles are also expected to be very similar for the 2008 and 2009 boreholes (based on gas age distributions). Data from 2008 boreholes were thus used to help test two suspected outliers in the 2009 borehole.

Suspected outliers or spurious data points were rejected by applying Peirce's criterion (Ross, 2003). Additionally, if a suspected outlier did not meet the criterion but was very close to meeting it and the same flask showed elevated values for other species, it was also rejected. Furthermore, several points were rejected because mole fraction results deviated from the seasonal cycle behavior of the species and values seen at adjacent depth levels. Overall, applying the data filtering resulted in $6,5,1,1,3$, and 6 eliminated data points for ethane, propane, $i$-butane, $n$-butane, $i$-pentane, and $n$-pentane, respectively.

For the 2008 EU borehole, the MPI-UEA data were placed on the INSTAAR scale by determining the average offset between the two data sets. These two data sets were then averaged, and the combined data set was used for atmospheric history reconstructions. Data from the 2008 US borehole and the 2009 borehole were treated separately for the atmospheric history reconstructions (Sect. 3.2).

The NOAA-INSTAAR network data were subjected to data curve fitting protocols, then filtered for outliers, and fit to a function comprised of a harmonic component and 

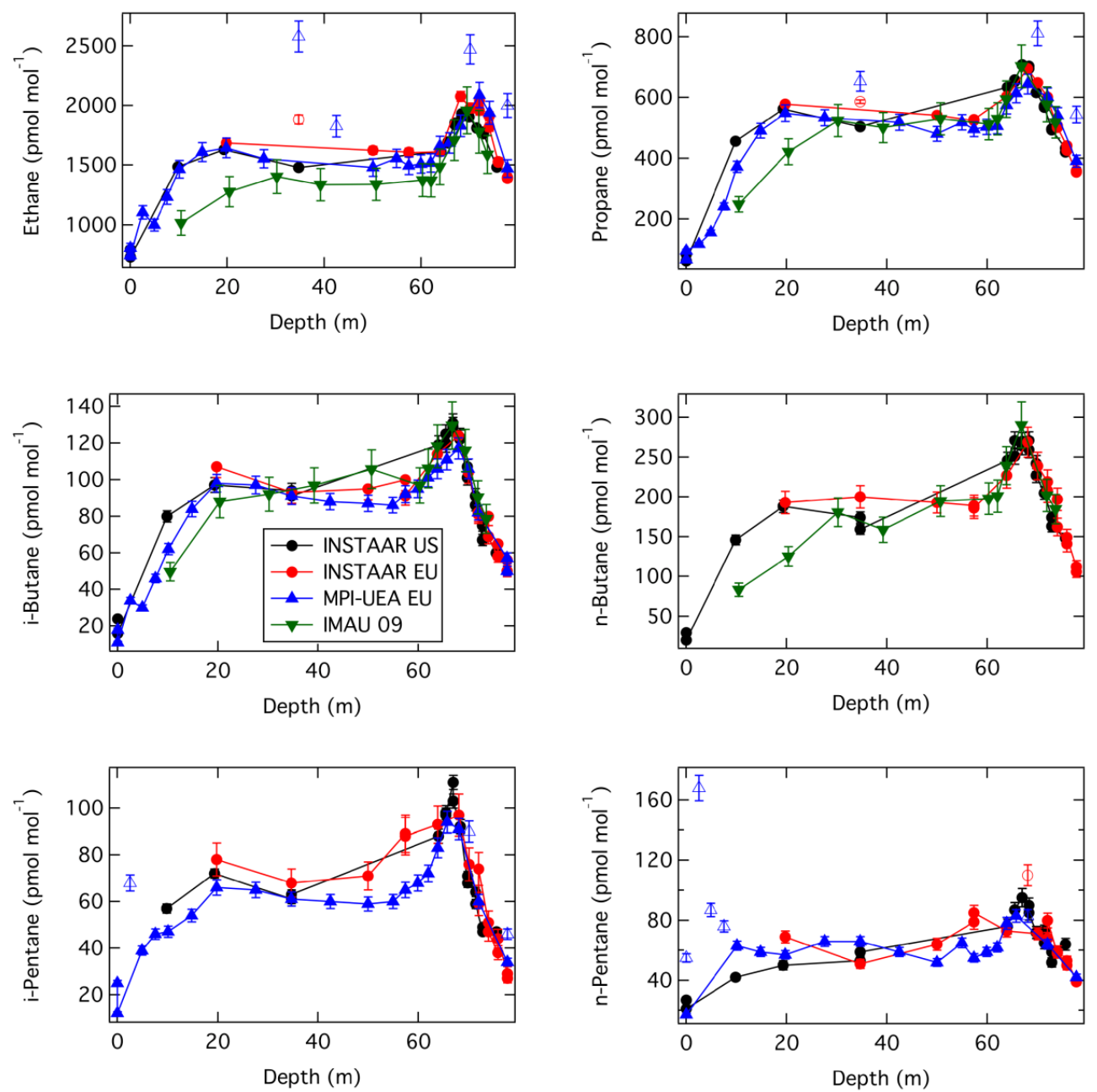

Fig. 2. Firn air depth profiles of ethane, propane, $i$-butane, $n$-butane, $i$-pentane and $n$-pentane (in pmol mol ${ }^{-1}$ ) from the three boreholes. Two sets of samples were collected from the EU hole and analyzed independently by two laboratories as indicated in the figure legend. Data points that failed the quality control filters and that were excluded from the data set used for atmospheric trend reconstruction are shown as open symbols.

polynomial term as described by Thoning et al. (1989) and Masarie and Tans (1995). Short-term variations in the data were smoothed by applying a Fourier-transform algorithm and long-term trends were determined after removing the short-term fluctuations and the annual harmonic cycle component. After applying the quality control filters, approximately 500 data points remained for each site and NMHC. Figure 3 shows for example the results for ethane determined in samples from Summit. Displayed are all available flask data. Data points that were rejected from the trend analyses are displayed as open diamonds, retained data are shown as full diamonds. The result for the trend analysis, used later in this work in conjunction with the reconstructed firn air histories, is displayed as the black line.

\subsection{Firn air modeling and inverse modeling}

The reconstruction of atmospheric trace gas histories from firn air measurements involves two main steps. First, the transport and mixing of trace gases in the firn column must be characterized for each site by determining the effective gas diffusivities at each depth level in the firn in "forward" gas transport models (Buizert et al., 2012). Such models take a trace gas history at the surface as input and produce a depth mole fraction profile for a given sampling date as the output. To ensure that the models contain an accurate parameterization of the gas transport processes, they are tuned and tested using trace gases with well-known atmospheric histories (see Buizert et al., 2012). Once the forward models are tuned and tested, they can be used to generate depth - gas age distribution matrices for the gas of interest. The measured depth mole fraction profiles are then combined with the depth - gas 


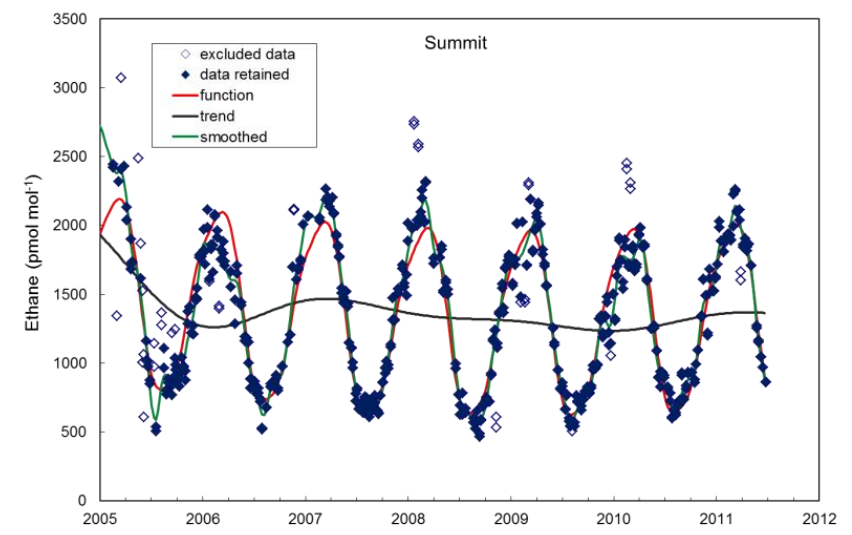

Fig. 3. Ethane in ambient air determined in flask samples collected at Summit, Greenland, between 2005 and 2011. The graph displays all individual data points as diamonds. Points that were rejected for the trend analyses are displayed as open symbols. Also shown are the best fit solutions for the smoothed annual cycle, the seasonal harmonic fit component (function) and the trend for the period of the available data.

age matrices in an inverse model to reconstruct atmospheric histories.

The LGGE-GIPSA firn gas transport model was the primary forward model used for this study; this model has been described in detail in Witrant et al. (2012). NMHC diffusion coefficient ratios with respect to $\mathrm{CO}_{2}$ were calculated with the parameterization by Chen and Othmer (1962), using critical temperature and volume data from Daubert (1996) and Ambrose and Tsonopoulos (1995) and are presented in Table 1, and compared with the values used by Worton et al. (2012) in Supplement Sect. Table S1. The INSTAAR forward model (Buizert et al., 2012) was also used for testing the dependence of reconstructed atmospheric NMHC histories on different representations of firn physics and for comparing upper firn hydrocarbon data with recent atmospheric histories from direct measurements. Both the LGGE-GIPSA and the INSTAAR forward models were part of a recent firn model intercomparison exercise for the NEEM site, where both models were found to achieve good results (Buizert et al., 2012).

The inverse model described in Witrant and Martinerie (2013) was used for the atmospheric history reconstructions. This is the most recent version of the LGGE-GIPSA atmospheric trend reconstruction model, based on Rommelaere et al. (1997) and Lukas (2008), and has been been detailed in more depth in Sapart et al. (2013) and Petrenko et al. (2013). The inverse model cannot reconstruct seasonal variations, as discussed in Wang et al. (2012). The effect of seasonality on NMHC depth profiles in firn is evaluated and discussed in Sect. 3.2.

\section{Results and discussion}

\subsection{Depth profiles}

There are some subtle differences in the four data sets shown in Fig. 2; however, there is overall good agreement in the absolute levels and the vertical depth profile behavior. All NMHC species show sharp increasing NMHC mole fractions from the surface to a depth of $\sim 20 \mathrm{~m}$. Below $20 \mathrm{~m}$, the NMHC depth profiles show relatively little change to a depth of $\sim 55 \mathrm{~m}$. Below $55 \mathrm{~m}$ NMHC mole fractions increase by on average $20-30 \%$, reaching maximum values at $\sim 70 \mathrm{~m}$. Below $70 \mathrm{~m}$ NMHC mole fractions decline steeply, eventually to lower levels than seen in the entire, non-seasonally influenced portion of the borehole. Ethane deviates from the other NMHC; its mole fraction in the lowest portion of the profile is about the same as in the $20-50 \mathrm{~m}$ zone. The agreement seen between the three different holes is consistent with the hypothesis that these gases are well preserved in the NEEM firn air and there is only little spatial variability in the scale of the separation of these three boreholes. The obvious increases in NMHC mole fractions in the $60-70 \mathrm{~m}$ zone indicate that NMHC levels increased in the past, then reached a maximum and have since declined in recent years. Furthermore, the similar behavior displayed by these six NMHC suggests similar histories and likely common emission sources of these gases.

The utility of using firn air records of NMHC for reconstructing their past atmospheric mole fractions relies on the assumption that NMHC do not undergo chemical changes in the firn. This was investigated by two different approaches. First, a study was conducted involving a full year of weekly in situ measurements of NMHC in the atmosphere and in air withdrawn from firn air at $\sim 1 \mathrm{~m}$ depth (Helmig et al., 2013) at Summit. These measurements showed that light alkenes including ethene and propene were produced in the snowpack, with production being linked to solar irradiance. Light alkanes, however, including all gases considered in the NEEM firn borehole analysis, did not show significant differences in their mole fraction between the atmosphere and the firn air throughout the year. These findings show that these NMHC do not undergo rapid chemical or physical changes in the upper firn.

The second approach addressed the possibility of relatively slow production or consumption of the alkanes in deeper firn. One way to examine whether a gas species is well preserved in deep firn is to compare records from different drilling sites that are expected to have similar atmospheric histories. We present the first such comparison for the light alkanes between the NEEM results and data from the 2001 extraction NGRIP site (Worton et al., 2012). NGRIP, at $75.1^{\circ} \mathrm{N}, 42.3^{\circ} \mathrm{W}, 2917 \mathrm{~m}$ a.s.l., is slightly colder than NEEM, with a mean annual temperature of $-31.5^{\circ} \mathrm{C}$ (vs. $-28.9^{\circ} \mathrm{C}$ for NEEM). It is also located further inland and at a higher elevation on the Greenland ice sheet than 
NEEM (see Fig. 1), and for these reasons is expected to be a cleaner site with respect to the deposition of trace organic impurities that could potentially result in some in situ production of hydrocarbons. However, we are not aware of any studies that directly compare trace organic content between NEEM and NGRIP firn. Thus, if there were substantial in situ production or destruction of light alkanes in deep firn, one would expect to find differences between the two sites.

Comparing records of the light alkanes vs. depth at each site is not appropriate, as the gas age distributions differ between NEEM and NGRIP, both because of different sampling dates and because of physical differences in firn properties (e.g., ice accumulation rate). However, it is possible to achieve a meaningful comparison by plotting the species of interest vs. another trace gas species that is known to be well preserved in the firn and has a similar age distribution with depth. This was demonstrated to be an effective approach for carbon monoxide (CO) as was described in detail in Petrenko et al. (2013). In the Petrenko et al. (2013) study, CO was plotted vs. $\mathrm{CH}_{4}$ for NEEM, Summit, and NGRIP. The small difference in free-air diffusivities between $\mathrm{CH}_{4}$ and $\mathrm{CO}(9 \%)$ was found to result in negligible differences in age distributions between the two gases.

For the light alkane comparisons, we follow the approach of Petrenko et al. (2013), choosing a well-preserved "reference" trace gas for each of the alkane species that was measured at both NEEM and NGRIP and that has the most similar free-air diffusivity. For ethane, such a gas is $\mathrm{CO}_{2}$, with a $9.5 \%$ diffusivity difference. For propane, CFC-12 is the best match, with a slightly larger $(15 \%)$ diffusivity. CFC-12 is also an excellent reference gas for $i$ - and $n$-butane ( $2 \%$ diffusivity difference), and CFC-11 for $i$ - and $n$-pentanes ( 3 and $4 \%$ difference, respectively).

Figure 4 shows the NEEM-NGRIP comparison for each of the alkane species. We chose the NEEM 08 EU data set for this comparison, as the NEEM 09 data do not include pentanes (nor CFC-11), and the NEEM 08 US data do not include CFC-11 and CFC-12. As can be seen in the six illustrated comparison plots, both data series agree to within the margins of uncertainty of each measurement. The agreement between the two sites supports the hypothesis of good preservation of these considered six light alkanes at both sites. While we cannot rule out small in situ alterations that are within the measurement uncertainties, overall the records appear to be suitable for reliable atmospheric history reconstructions.

\subsection{Seasonality in the upper $40 \mathrm{~m}$}

The declining NMHC mole fractions with decreasing depth in the upper $40 \mathrm{~m}$ of the profiles shown in Fig. 2 reflect the influence of fast gas exchange between the firn air and the atmosphere, which at the time of the sampling, i.e., midsummer, exhibits the seasonal minimum of the NMHC annual cycle (Fig. 3). The primary sink determining the re- moval of NMHC from the atmosphere is from reaction with the $\mathrm{OH}$ radical, which has a seasonal cycle that closely follows solar irradiance. Consequently, atmospheric NMHC levels exhibit strong seasonal cycles, the relative amplitude of which increases with increasing NMHC-OH reaction rate. This is particularly pronounced in the Polar regions, due to the more dramatic change in the seasonal solar irradiance with increasing latitude. The seasonal cycle for ethane from the NOAA-INSTAAR global flask network data depicted in Fig. 3 shows that ethane increases $\sim 3$-fold from a summer minimum of $\sim 600 \mathrm{pmol} \mathrm{mol}^{-1}$ to $\sim 2000 \mathrm{pmol} \mathrm{mol}^{-1}$ during the winter. To further illustrate the dependence of the seasonal cycle on the molecule size, in Fig. 5 the mean seasonal $\mathrm{C}_{2}-\mathrm{C}_{5}$ NMHC cycles observed in the Summit in situ data are shown, normalized to their maximum seasonal value. The relative amplitude of the seasonal cycle increases, the onset of the spring decline occurs progressively sooner, and the length of the summer minimum increases with increasing molecule size. This behavior reflects the rate of atmospheric oxidation, which increases with molecule size (i.e., resulting in progressively shorter atmospheric lifetimes for the heavier NMHC).

The effect of the seasonal NMHC cycle on mixing ratios in firn can be evaluated using the atmospheric record as input in a forward model describing trace gas transport in firn air. Atmospheric NMHC data are not available for the NEEM site. The closest site for which seasonal NMHC data exist is Summit. Summit is located $\sim 650 \mathrm{~km}$ to the SE and, at $3200 \mathrm{~m}$ a.s.l., at an elevation $716 \mathrm{~m}$ higher than NEEM. There are four other Arctic sites (defined as located north of the Arctic Circle), i.e., Alert, Barrow, Ny-Alesund, and Pallas, and the sub-Arctic site Stohofdyi on Iceland at $63.33^{\circ} \mathrm{N}$, for which NMHC records from the NOAA-INSTAAR VOC monitoring program are available (Fig. 1). The 2005-2012 data from these sites were used to evaluate how the seasonality in the upper firn impact the NEEM firn record. Mean monthly mole fractions were calculated, then the mean seasonal cycle was defined as the average of the multi-year monthly mean mole fractions.

The seasonal NMHC cycles for these six sites show similar relative seasonality; however, absolute NMHC mole fractions show geographic variations that are especially visible in winter. These are high enough to affect the overall mean annual mole fraction. In order to illustrate the effect of atmospheric seasonality in NMHC mole fraction on the firn air, idealized atmospheric scenarios were built by cyclically reproducing the mean seasonal cycle at these six Arctic sites during the past several decades. These simulations were initiated during mid-July, the approximate date for the firn air sample collection. Figure 6 shows the results obtained when using these idealized scenarios as input to the LGGE-GIPSA forward firn model in comparison with the NEEM data. It can be seen that seasonality affects NMHC firn air mole fractions in the upper 30 to $40 \mathrm{~m}$. Below $40 \mathrm{~m}$ depth, modeled NMHC 

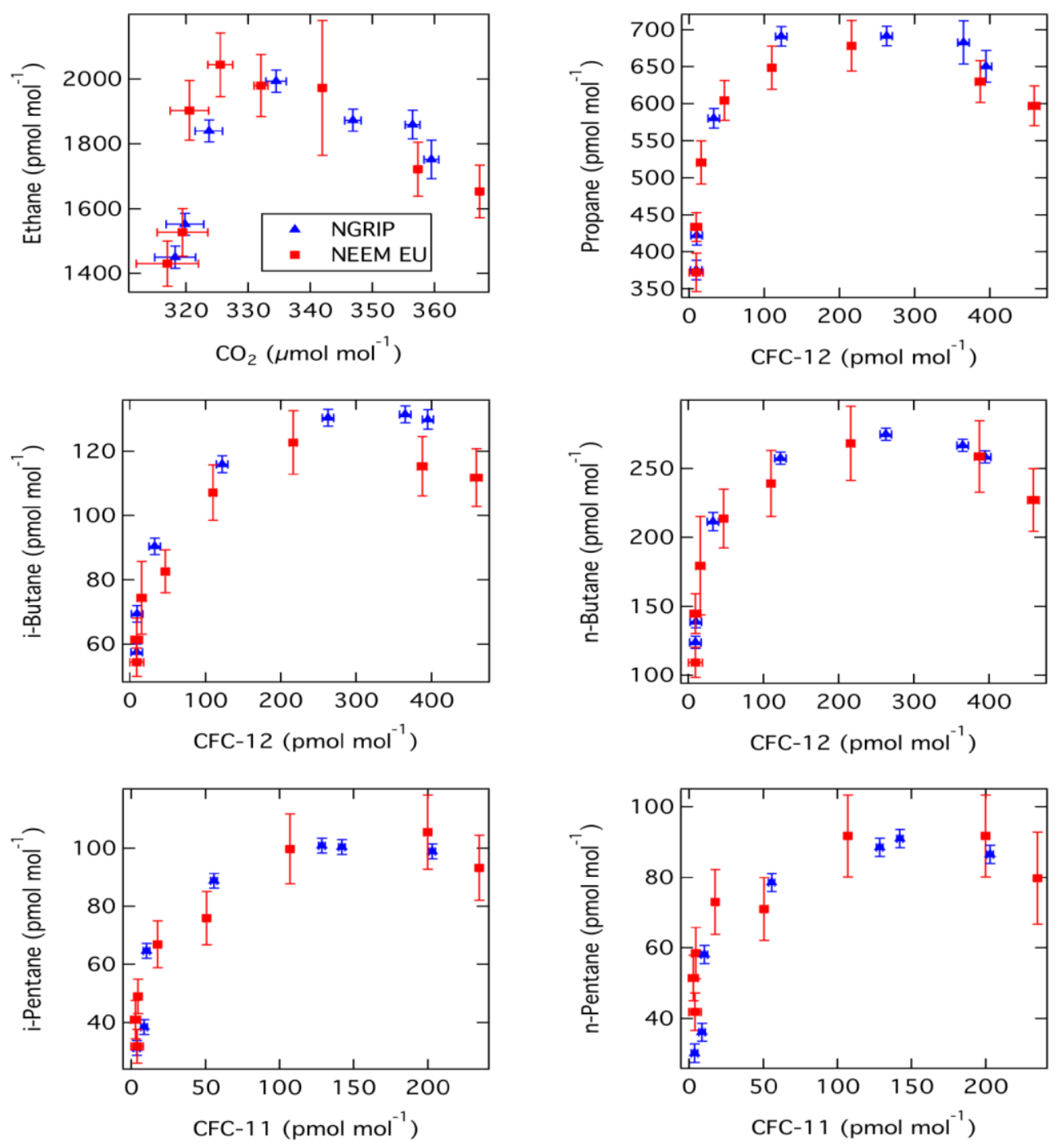

Fig. 4. NMHC to $\mathrm{CO}_{2}$ and CFC relationship in the NEEM 08 EU and NGRIP firn air data. Error bars represent the 1- $\sigma$ standard deviation in the data where available.

mole fractions become stable, indicating the loss of a seasonal signature influence.

The results in Fig. 6 also show distinct differences in the model output depending on which of the site data sets are used. Considering both the mean level and seasonality, none of these monitoring sites yielded consistent agreement with the NEEM firn data. Due to the differences seen in absolute levels between the ambient air records for different compounds at different sites and the NEEM data, and challenges in applying a uniform, well-characterized scaling factor to correct for these differences, we decided not to use firn data above $30 \mathrm{~m}$ depth for the trend scenario reconstruction presented in the following section.

\subsection{NMHC history reconstructions}

The inverse modeling was first applied separately to data from each borehole to allow for the assessment of the sensitivity of reconstructed scenarios to the slight differences seen between individual borehole data sets (see Supplement Fig. S1). Despite the limited number of data points and slight deviations in the data between labs and boreholes the inverse modeling results display good agreement in the representation of the atmospheric NMHC histories. The years of observed maximum mole fractions all fall around 1980 for propane-pentanes and vary by less than $10 \mathrm{yr}$ for individual data set results. The variability for ethane is a bit larger, but remarkably all model results show ethane peaking significantly earlier. Secondly, reconstructed NMHC maximum mole fractions agree to within $<10 \%$ between different boreholes. Since deviations between the results from different 


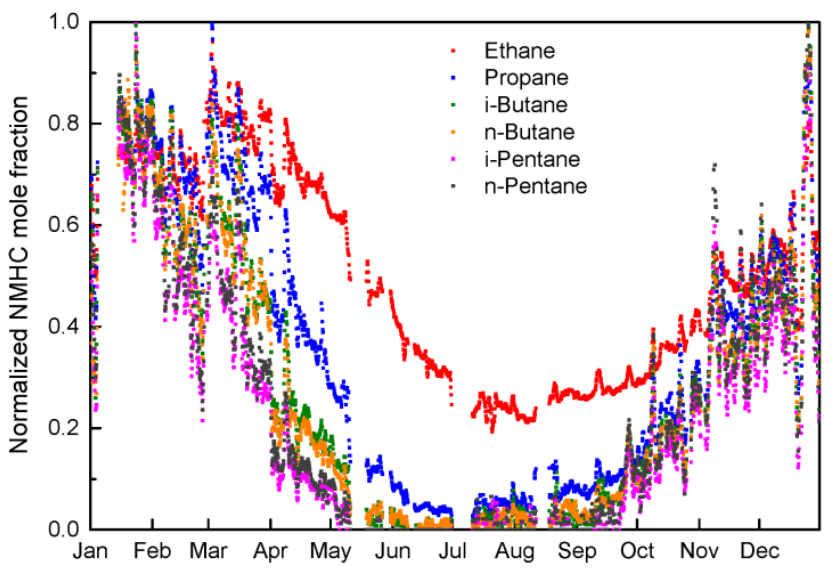

Fig. 5. Annual cycle of ethane, propane, $i$-butane, $n$-butane, $i$ pentane and $n$-pentane at Summit from in situ measurements collected during 2009 with the data normalized to the observed seasonal maximum value.

laboratories and boreholes were minor, the data for all boreholes were used in a multi-borehole constrained reconstruction of the NMHC histories shown in Fig. 7.

In order to test the effect of model vs. firn data discrepancies, the multi-hole constrained simulations were performed in two different manners, as in Sapart et al. (2013). (1) Data from the three boreholes were weighted equally (in black in Fig. 7). (2) Each of the three boreholes was weighted by the inverse of the root-mean-square deviation (RMSD) between model results and firn data calculated from the single-hole constrained simulations (see Supplement Fig. S3). The two treatments displayed in Fig. 7 led to very similar results for all species, indicating that the reconstructed scenarios are not significantly affected by slight differences in data and modeling quality between boreholes. NMHC maxima consistently occur around $\sim 1980$, except for $\mathrm{C}_{2} \mathrm{H}_{6}$, which peaks $\sim 10$ years earlier. For a better comparison between compounds, in Fig. 8 all reconstructed trends were normalized to the beginning of the record and plotted together. This display re-emphasizes the similar temporal behavior of the $\mathrm{C}_{3}-\mathrm{C}_{5}$ NMHC, with all of these species peaking from 1980-1985, and the ethane maximum occurring approximately in 1970 . Another interesting result is that the relative changes seen over the period of the atmospheric reconstruction are quite different. The year 2010 NMHC mole fraction in comparison to its maximum in 1970 has declined to $\sim 68 \%$ for ethane, and in comparison to the maxima around around 1980 to $65 \%$ for propane, $63 \%$ for $i$-butane, $51 \%$ for $n$-butane, $42 \%$ for $i$-pentane, and $50 \%$ for $n$-pentane. It is interesting to note that these relative changes scale with the lifetime of the NMHC, with the smallest relative change seen for ethane, the longest-lived compound, and the highest relative changes seen for the pentane isomers, which are the shortest-lived compounds in this NMHC series. This points towards relatively higher emission reductions for the heavier, gasoline- type NMHC species in comparison with the lighter natural gas associated NMHC.

\subsection{Comparison of reconstructed NMHC histories with modern observations}

The NOAA-INSTAAR NMHC monitoring program started in 2005, with data until mid-2011 fully processed at this time. While this record is too short for a standalone trend analysis, the available data offer an opportunity to compare the tail end of the NEEM firn air reconstructed histories with actual ambient observations. The results from these analyses are added to the firn air model NMHC history reconstruction in Fig. 9. For all compounds there is a good match between the firn reconstructions and monitoring results. The deviation between the reconstructed trends and the data from the five sites is well within the range of the deviation between the monitoring sites. All data tendencies point towards declining NMHC levels, in agreement with the model reconstruction. The site data do not provide support for the reversal towards increasing mole fractions for propane and $i$-butane simulated by the model. It should be noted that the flattening of the slope, respectively reversal of the trend in the last few years in the modeled results for propane and $i$-butane are not significant in comparison with the uncertainty envelopes in Fig. 7a, consequently there is no disagrement between these two analyses.

\subsection{NMHC ratios}

Numerous studies have shown that the light NMHC are emitted in relatively constant ratios by their individual sources. This feature offers opportunities to use NMHC ratios to investigate NMHC sources and atmospheric oxidation processes. For instance, the ratio of $i$ - over $n$-pentane is significantly lower in emission from oil and gas emissions (reported values for $i / n$-pentane $\sim 0.9$ ) than in urban environments ( 2.4 [Pasadena] (Gilman et al., 2013)). At remote monitoring sites, such as on Pico Mountain in the Azores, Portugal, a geometric mean $i / n$-pentane ratio of 1.28 was determined (Helmig et al., 2008). The isomeric $i / n$-butane pair has been shown to be rather constant in data from a wide array of sampling environments. Most studies report values between 0.37-0.57 (Parrish et al., 1998). While the two butane isomers have similar $\mathrm{OH}$ reaction rate constants, their reaction with $\mathrm{Cl}$ differs by $\sim 50 \%$, with faster removal of the $n$ isomer. Deviations in the $i / n$-butane ratio have therefore been used to identify chlorine chemistry influences (Jobson et al., 1994; Gilman et al., 2010). In a recent study at a seasonally covered site in NE Utah, significant shifts in butane and pentane isomer ratios were observed, and this behavior was used to infer chlorine reactions in this continental snowpack (Thompson et al., 2014).

While analyses of these isomeric ratios have been applied in numerous studies, to the best of our knowledge thus far 

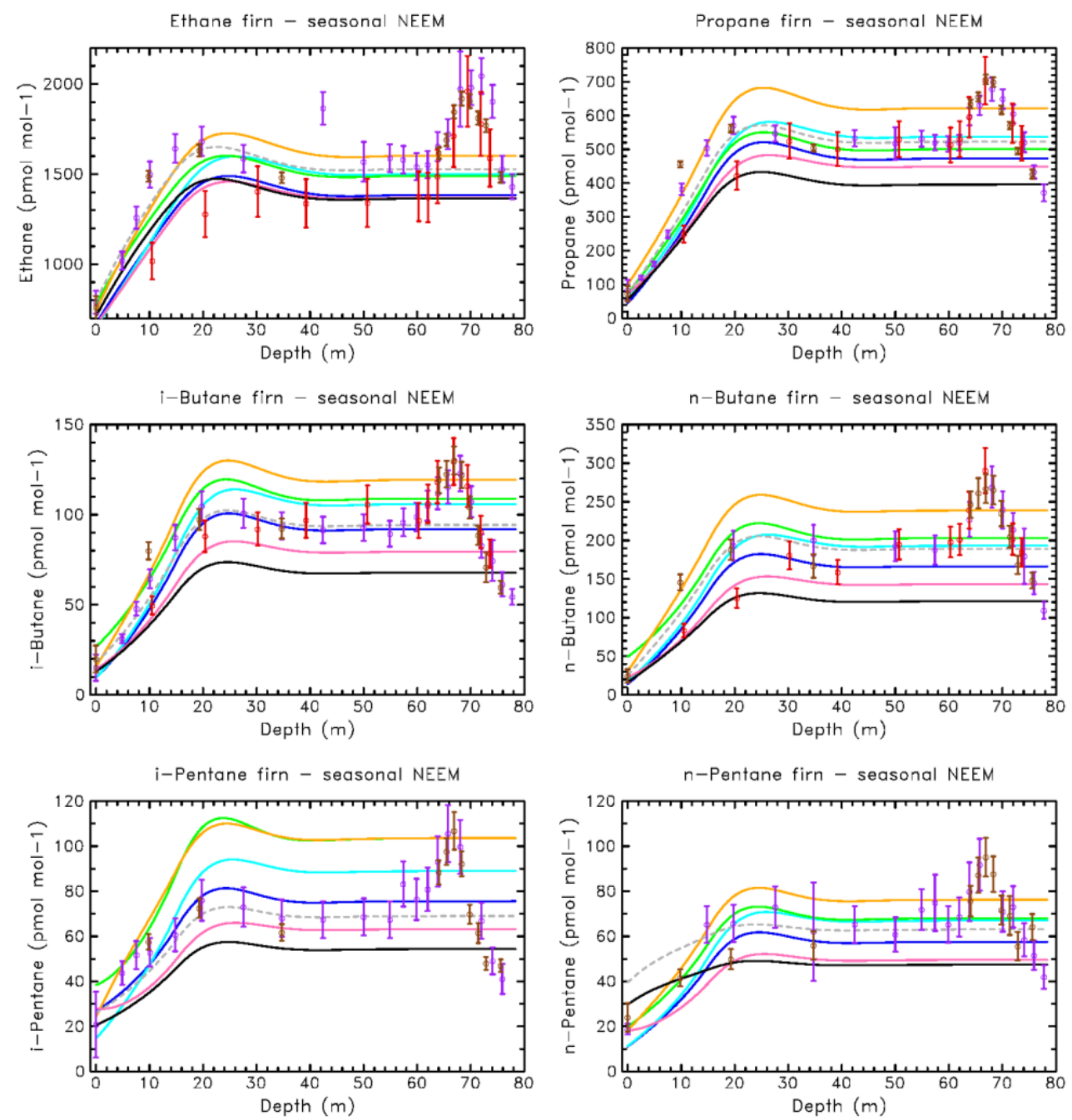

Fig. 6. Impact of atmospheric seasonality on NMHC mole fractions in the firn profile. Circles: measured mole fractions in firn. Color key: NEEM-EU - purple, NEEM-US - brown, NEEM-09 - red. Colored lines show mole fractions calculated with mean atmospheric seasonality. Alert - dark blue, Svalbard - clear blue, Summit - black, Barrow - green, Finland - orange, Iceland - pink. The dashed grey line represents a best fit to the NEEM data by tuning the model using scaling factors applied to the Summit data. Error bars indicate estimated $2 \sigma-$ uncertainty in the data.

there have been no investigations of the behavior of these isomer ratios in long-term data sets. Consequently, the NEEM firn air results offer a unique opportunity to expand upon these previous studies and to provide new bases for comparing isomeric NMHC ratios to a historical record and potentially to deduce changes in primary emissions sources.

Figure 10 presents the reconstructed trends of the $i / n$ butane and $i / n$-pentane isomers and their respective ratios. For the butane isomers, an $i / n$-butane ratio of $\sim 0.4$ was calculated for prior to 1950 , increasing to $\sim 0.5$ by 1970 and then remaining relatively stable until 2000. The $i / n$-butane ratio appears to increase after $\sim 2000$; however, this increase in the firn air model results is not statistically significant, as discussed for the $i$-butane trend in the previous section. For comparison, the Summit ambient air flask data show an $i / n$ - butane ratio of 0.50 for the most recent years, with no discernible upward trend. Furthermore, the median $i / n$-butane ratio (0.53) in the $2 \mathrm{yr}$ in situ data from Summit included in Fig. 10 is just slightly higher than the flask record and further constrain the modern ratio of this isomer ratio.

Similar to the butane pair, the $i / n$-pentane ratio shows an increase during the first part of the record. The relative change in the isomeric ratio is larger for the pentanes, with a $\sim 63 \%$ increase of the ratio between 1950 and 1970. The decline seen in the firn air model results during the most recent years is not apparent in the Summit in situ record. The apparent decline in the modeled ratio is probably due to the relatively higher error in the simulation and is not statistically significant. 

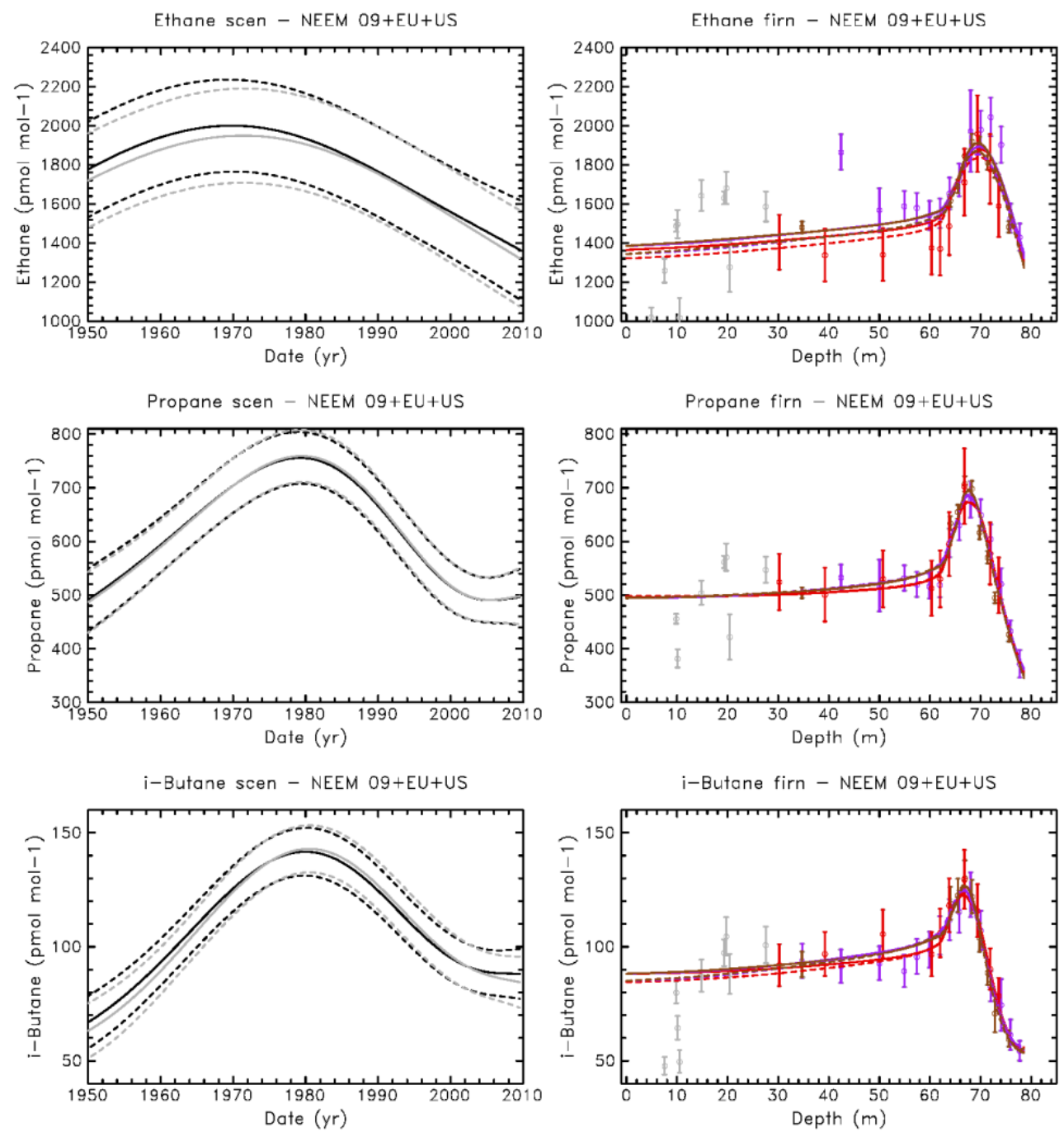

Fig. 7a. Multi-borehole constrained atmospheric trend reconstructions (left) for ethane, propane and $i$-butane. The black lines show results for all three boreholes being weighed equal. The grey lines in the left panel and dashed lines in the right panel show results for weighing each hole by the inverse root-mean-square deviation (RMSD model-data) in the single hole inversions (see text). Dotted lines in the left graphs indicate the 2- $\sigma$ confidence interval of the results. The right panel shows the results from the LGGE-GIPSA forward model that used the reconstructed histories as input. Colors used for firn data and forward model runs are: NEEM-EU - purple, NEEM-US - brown, NEEM 2009 - red.

There are a number of possible drivers that may cause a shift over time in these isomeric NMHC ratios. These include changes in emission types and emission ratios in the source regions of these compounds, or possibly a change in air transport patterns, with air from different regions representing different emission types/ratios being brought to the NEEM site. Another explanation might be a change in the chemical sinks, for instance changes in the relative contribution of atmospheric chemical oxidation pathways (such as a shift in the relative contribution of $\mathrm{OH}$ vs. other oxidants (e.g., $\left.\mathrm{Cl}, \mathrm{NO}_{3}\right)$ ). Such a shift was considered in Aydin et al. (2011) in regards to changes in the methane to ethane ratio inferred from firn air at Summit. As OH concen- trations inferred from methyl chloroform observations were determined to have relatively small interannual variability and no overall increasing or decreasing trend in the period 1979-2003 (Prinn et al., 2005; Montzka et al., 2011), an increase in other radical sources would be necessary to explain the observed increase in the isomeric NMHC ratios. The increase in the $i / n$-isomer ratio in the earlier part of the record would be in agreement with a relatively higher oxidation ratio by the $\mathrm{Cl}$ radical, which reacts faster with the $n$ isomer, resulting in an increase in the $i / n$ ratio. Anthropogenic activities serve as a significant source of reactive chlorine species for the troposphere (Graedel and Keene, 1995; Tanaka et al., 2000, 2003), and several works have 

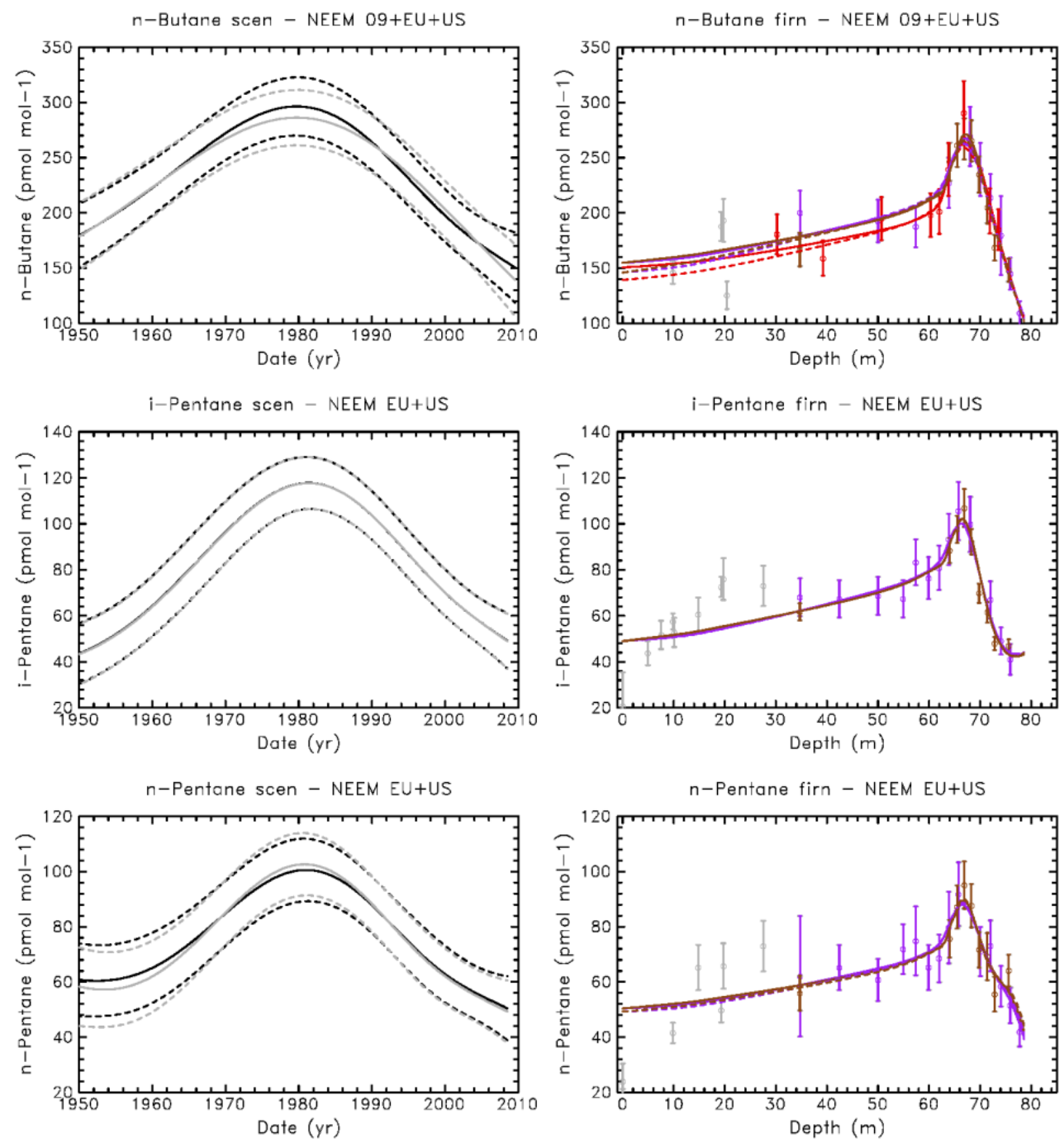

Fig. 7b. Same as Fig. 7 a for $n$-butane, $i$-pentane and $n$-pentane.

determined an increasing trend in tropospheric chlorine compounds from the 1970s to the mid-1990s (Rasmussen and Khalil, 1986; Prinn et al., 1992; Mahieu et al., 2004). Significant increases in nitrogen oxides $\left(\mathrm{NO}_{\mathrm{x}}\right)$ since 1980 were also determined from firn air histories at Summit (Worton et al., 2012). This, along with increases in acidic aerosols, may contribute to increases in $\mathrm{Cl}$ radical concentrations (e.g., Thornton et al., 2010; Mielke et al., 2011), however, long term historical observations of atmospheric chlorine, which could have driven the pentane isomers towards a higher $i / n$ ratio value, are not available for comparison..

Another, and possibly more likely scenario, is that the increase in the $i / n$-pentane ratio between 1950 and 1970 is indicative of changes in the relative importance of different VOC sources. Measurements influenced by anthropogenic emission sources have yielded $i / n$-pentane ratios on the order of $\sim 1.8-2.5$. Both boreal biomass burning and oceanic sources preferentially emit $n$-pentane, resulting in lower $i / n$-pentane ratios for these source signatures. Andreae and Merlet (2001) determined an $i / n$-pentane emission ratio for extra-tropical forest fires of $\sim 0.5$. These emission data are confirmed by measurements taken at Pico Mountain that showed significantly different $i / n$-pentane ratios in air masses impacted by summertime boreal fires (ratio of 0.73) compared to non-fire-influenced events (ratio of 1.61) (Helmig et al., 2008). Natural oceanic emissions have also been shown to have greater fluxes of $n$-pentane relative to $i$-pentane. Broadgate et al. (1997) determined an $i / n$ pentane ratio from oceanic fluxes in the North Sea of 0.6. Ratios of 0.72 and 0.73 were also found for waters near Cape Grim, Tasmania, and Mace Head, Ireland (Lewis et al., 2001). Therefore, the increase in the $i / n$-pentane ratio in the earlier part of the record, synchronous with increases in the absolute NMHC mole fractions, is in agreement with 


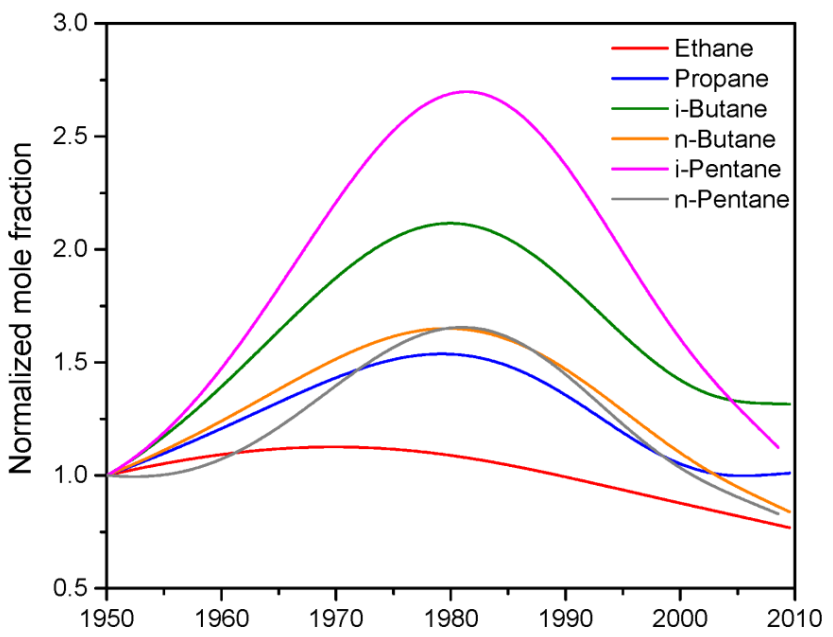

Fig. 8. Reconstructed NMHC trends normalized to 1950.

a stronger influence of fossil-fuel sources on the NMHC signature. The ratio of the butanes is similar for fossil fuels, biomass burning, and oceanic emissions (Lewis et al., 2001; Helmig et al., 2008); thus, the butane ratio cannot be used to tease out changes in relative source contributions.

\subsection{Comparison of reconstructed NMHC histories with emission estimates}

NMHC constitute a major fraction of VOC, which play an integral role in the production of tropospheric ozone. The amount of ozone produced varies by NMHC species and depends on the levels of available $\mathrm{NO}_{\mathrm{x}}$ and radical conversion rates. Lamarque et al. (2005) concluded that changes in $\mathrm{NMHC}$ and $\mathrm{NO}_{\mathrm{x}}$ concentrations were the primary cause of 20th century increases in tropospheric ozone. Consequently, VOC speciation and trends are important inputs in model descriptions of tropospheric ozone trends.

There are few atmospheric records that allow assessment of the change in NMHC or VOC emissions over the past century. Modeling work, in many cases, has to rely on inventories that are derived from the accumulation of best estimates of emissions. An overview and compilation of several emissions databases (including EDGAR, RETRO, and regional scale databases) and reconstruction of historical trends were presented by Lamarque et al. (2010). That study presented estimates for total VOC, which besides NMHC includes an array of other volatile organic compounds, such as aromatics, oxygenated VOC and organic acids. Nonetheless, NMHC constituted the largest fraction of considered VOC. Assuming that the relative distribution of contributing compounds has remained relatively constant, the NEEMdata reconstructed NMHC trends should provide a reasonable VOC surrogate for comparison and evaluation of these emission estimates. As the NEEM observations are deemed to be mostly representative of Northern Hemisphere (NH)
NMHC emissions and atmospheric composition, emission estimates from $\mathrm{NH}$ source regions were extracted from the Lamarque et al. (2010) emissions database and compiled. Results from the emissions database and the NEEM firn data in Fig. 11 show increasing levels in the middle part of the 20th century followed by a stabilization and decline during the latter part. The magnitude and timing of these trends, however, are markedly different. The total NMHC carbon atom mole fraction from the NEEM data (black trace in the top panel) increased by approximately $50 \%$ after 1950 , reaching a maximum around 1980, and has since declined to close to year 1950 levels. The rate of decline appears to be somewhat faster than the rate of increase in the earlier part of the record. Total NH VOC emissions represented by the database (lower panel, blue data) show a relatively larger rate of increase ( $\sim$ doubling), reaching a maximum around 1990, and leveling off at a much slower rate thereafter. These are notable differences between the two records. We therefore investigated the potential of spatial changes in emissions, in particular the question if the difference between the two series could be due to emissions from Asia, which have increased significantly during the past 10-20 yr (Ohara et al., 2007). Greenland is mostly subjected to transport from $\mathrm{Eu}-$ rope and to some smaller fraction from North America, but very little from Asia (Kahl et al., 1997; Eckhardt et al., 2003; Klonecki et al., 2003; Stohl, 2006; Helmig et al., 2007). To investigate the possible reflection of these different trends, emission data from the US and Canada and from West European regions were separated from the total $\mathrm{NH}$ record. The US/Canada/Western Europe results, shown as black data in the lower panel of Fig. 11 and scaled on the right $x$ axis, show much better agreement between the timing of the emissions maximum and the NEEM reconstructed NMHC trends. There is, however, a notable discrepancy in the magnitude of the relative signal, with the emissions increase being more than two times as large as the increase seen in the reconstructed NMHC ambient air mole fractions. It should be noted that $\sim 70 \%$ of the total NMHC signal is constituted by ethane and propane, compounds with lifetimes on the order of $>1$ week. Consequently, this comparison may be flawed by the fact that gas species retrieved from the firn air are on average longer lived than VOC species considered in the emissions database. This comparison suggests that emission reductions have likely been more effective for shorterlived compounds (higher molecular weight VOC) than for the longer-lived species (ethane, propane).

In conclusion, the Greenland firn air record likely reflects emission changes in Europe (and North America) more than the $\mathrm{NH}$ average, and may not be as sensitive to emissions from East Asia. Moreover, comparison of the firn air record with emission inventories suggests that relative changes seen in the light NMHC, while showing similar tendencies as emission estimates, do not necessarily reflect the relative magnitude of VOC emission changes in source regions. 

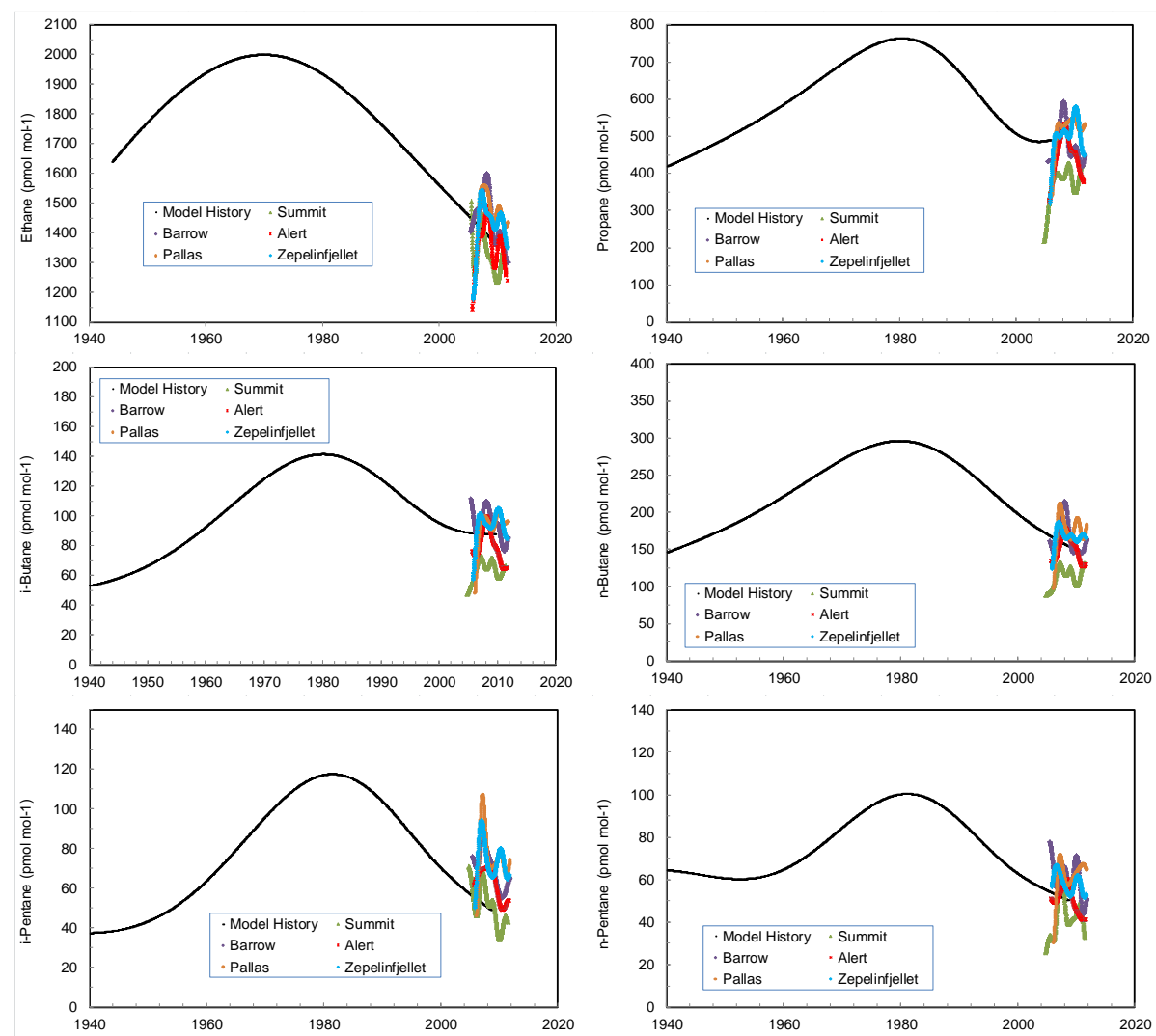

Fig. 9. NMHC reconstructed histories based on the NEEM firn air data in comparison with trends (see Fig. 3 for ethane Summit example) derived from 2005-2011 NOAA-INSTAAR VOC network data at five Arctic sites.

\subsection{Trend analyses and comparisons with other records}

Several other recent studies have investigated NMHC histories during periods that overlap with the NEEM records. Aydin et al. (2011) used firn air records from Summit, and two Antarctica sites, the West Antarctic Ice Sheet Divide and the South Pole, to reconstruct the ethane history. Due to the lower snow accumulation rate, the Antarctica records allowed the reconstruction back to $\sim 1900$. Worton et al. (2012) analyzed the same $\mathrm{C}_{2}-\mathrm{C}_{5}$ NMHC reported in this study in firn air from NGRIP retrieved in 2001 (Fig. 1). The findings from the two other Greenland firn air retrievals, presented as the NMHC maxima and the inferred approximate year of the occurrence of the maximum in comparison with the findings from this study, are summarized in Table 2.

Results from all three Greenland firn air studies show remarkable agreement, considering that these data were obtained from three different boreholes, and retrieved at different times (with the NGRIP borehole used in the Worton et al. (2012) study drilled 7-8 yr earlier than NEEM) using different extraction systems, NMHC quantifications from different laboratories, and three different firn air diffusion models and reconstruction methods. All three studies agree on showing a decrease in NMHC in recent years. The historical NMHC mole fraction maxima generally agree to within better than $10 \%$. There is, however, a notable difference in the simulated timing of the maxima. While our results for propane through pentane agree well to within $3-5 \mathrm{yr}$ with the NGRIP findings, the ethane peak time derived from the NEEM data is $\sim 7-10 \mathrm{yr}$ earlier than what was calculated for the Summit and NGRIP data sets. The NGRIP data were made available to us, and NEEM + North GRIP multi-site constrained scenario reconstructions were performed (see Supplement Fig. 3 and Supplement Note about NEEM-North GRIP comparison). The results for all species are consistent within error bars for the NEEM-only based scenarios, and the ethane peak date remains in the early 1970s. When results from the NEEM boreholes and data from the different laboratories are considered individually (Fig. S1a), they all result in ethane peak times prior to 1980. The firn record at NEEM has been analyzed for more species than any other site, making the age of the firn air at NEEM the best constrained. However, it should be noted that while we determined an earlier peak time consistently in our modeling results, the peak of the ethane maximum is relatively flat and our determined ethane peak time and the Worton et al. (2012) and Aydin et al. (2011) results overlap within the uncertainty estimates of these studies. 
Table 2. Comparison of reconstructed NMHC maxima from three independent studies using firn air profiles on the Greenland ice sheet.

\begin{tabular}{|c|c|c|c|c|c|c|c|c|c|}
\hline & \multicolumn{3}{|c|}{ NEEM (this study) } & \multicolumn{3}{|c|}{ Summit (Aydin et al., 2011) } & \multicolumn{3}{|c|}{ NGRIP (Worton et al., 2012) } \\
\hline & $\begin{array}{r}\text { Maximum } \\
\mathrm{nmol} \mathrm{mol}^{-1}\end{array}$ & $\begin{array}{r}\text { Year of } \\
\text { Maximum }\end{array}$ & $\begin{array}{r}\text { Year } 2000 \\
\text { nmol mol }\end{array}$ & $\begin{array}{r}\text { Maximum } \\
\mathrm{nmol} \mathrm{mol}^{-1}\end{array}$ & $\begin{array}{r}\text { Year of } \\
\text { Maximum }\end{array}$ & $\begin{array}{r}\text { Year } 2000 \\
\mathrm{nmol} \mathrm{mol}^{-1}\end{array}$ & $\begin{array}{r}\text { Maximum } \\
\mathrm{nmol} \mathrm{mol}^{-1}\end{array}$ & $\begin{array}{r}\text { Year of } \\
\text { Maximum }\end{array}$ & $\begin{array}{r}\text { Year } 2000 \\
\mathrm{nmol} \mathrm{mol}^{-1}\end{array}$ \\
\hline Ethane & 2.00 & 1970 & 1.56 & 2.0 & Late $1970 \mathrm{~s}$ & 1.5 & 2.2 & 1977 & 1.4 \\
\hline Propane & 0.76 & 1979 & 0.52 & & & & 0.76 & 1980 & 0.45 \\
\hline$i$-Butane & 0.14 & 1980 & 0.095 & & & & 0.14 & 1977 & 0.080 \\
\hline$n$-Butane & 0.30 & 1980 & 0.20 & & & & 0.32 & 1977 & 0.16 \\
\hline$i$-Pentane & 0.12 & 1981 & 0.070 & & & & 0.12 & 1978 & 0.058 \\
\hline$n$-Pentane & 0.10 & 1981 & 0.063 & & & & 0.11 & 1976 & 0.051 \\
\hline
\end{tabular}

The average decline rates for the reconstructed NEEM NMHC histories for the 1985-2000 period determined by linear regression are presented in Table 3. The average trends in the NMHC ambient air flask data mole fractions for years 2006-2011 were determined in a similar fashion and included in Table 3 for comparison with the firn histories reconstruction. The network data show declining NMHC ambient mole fractions for all species, in agreement with the firn air results. The rates of decline between both data sets and analysis approaches agree reasonably well within the margins of uncertainty in the determination. This agreement also indicates that the rates of decline do not appear to have changed notably during the most recent years. The relatively lower decline rate seen in the ethane trend in the firn data ( $1.0 \%$ for ethane vs. $2.0-2.7 \%$ for the other NMHC) is not noticeable in the results from the flask data set; however, this may be due to the relatively high uncertainty in the network data trend due to the shortness of the record.

Table 3 also lists for comparison the NMHC trend determinations from the Aydin et al. (2011) and Worton et al. (2012) reconstructions. The Worton et al. (2012) trend results tend to be at the higher end, with five of the six NMHC decline rates being larger compared to our and the Aydin et al. (2011) findings. This is most notable for ethane, where the Worton et al. (2012) trend is $\sim$ two times the one determined in the two other studies. Notably, the peak ethane firn values in Worton et al. (2012) and in our study are similar. Consequently, this difference in ethane decline rate possibly arises from the differences in the modeling methods used in the reconstructions, or the fact that our observations include 7-8 yr of more recent data, with the data from those years potentially influencing the record towards a slower rate of decline.

Simpson et al. (2012) recently used a long-term record, starting in 1984, of ambient air canister measurements across a north-south Pacific transect to deduce global ethane trends, also included in Table 3. These authors report that at high northern latitude, defined as $30-90^{\circ} \mathrm{N}$, ethane declined by an average of $-12.4 \pm 1.3 \mathrm{pmol} \mathrm{mol}^{-1} \mathrm{yr}^{-1}$ from 1984 to 2010 . The ethane declines seen in the NEEM, North GRIP, Summit, and in the ambient monitoring network data are all larger, by a factor of $\sim 2-3$. NMHC atmospheric mole fractions show a strong latitudinal gradient (Helmig et al., 2009; Simpson et al., 2012) with highest mole fractions observed at high latitudes. Consequently, the three firn air sites and Arctic network ambient monitoring sites, all located $>67^{\circ} \mathrm{N}$, are located where global atmospheric NMHC mole fractions are the highest. These areas, showing the overall highest atmospheric levels, are expected to show overall higher absolute rates of decline and consequently be sensitive regions for observing changes in atmospheric NMHC. The latitudinal gradient of ethane is $\sim 30 \%$ between 30 and $70^{\circ} \mathrm{N}$ (Helmig et al., 2009; Simpson et al., 2012). This gradient is smaller than the differences seen in the ethane decline rate seen in the Arctic and the Simpson et al. (2012) results. Consequently, the smaller decline rate seen by Simpson et al. (2012) probably again reflects the different air mass and source region representation of these data sets, i.e., the stronger influence of Asian emission trends on the Pacific transect data vs. a stronger North American and European signature in the Greenland data.

This difference will potentially become more significant in the future as the relative importance of Asian emissions continues to increase over the next decades, resulting in changes in atmospheric composition that are not necessarily reflected in the Greenland firn record.

The aforementioned studies have taken a closer look at emission types and sources that contributed to observed NMHC declines. A particular interest here was also to investigate methane to NMHC relationships and use NMHC signatures to better understand changes seen in atmospheric methane trends. Aydin et al. (2011) concluded that global ethane emissions from fossil fuel sources have dropped from their peak value of $14-16 \mathrm{Tg} \mathrm{yr}^{-1}$ to $8-10 \mathrm{Tg} \mathrm{yr}^{-1}$ and that these changes were accompanied by an increase in biomass burning emissions of $<1 \mathrm{Tg} \mathrm{yr}^{-1}$ in 1950 to $\sim 3 \mathrm{Tg} \mathrm{yr}^{-1}$ by 2000 , and then declining to $2 \mathrm{Tg} \mathrm{yr}^{-1}$. These estimates compare well with results from Simpson et al. (2012), who determined a decline in total ethane emissions of $21 \%$ from 14.3 to $11.3 \mathrm{Tg} \mathrm{yr}^{-1}$. Most of this decline is attributed to reductions in fossil fuel emissions, likely from reductions in fugitive emissions from natural gas development, from reduction in gas flaring, and from recovery of natural gas during the mining and processing of natural gas and oil. These works also concluded that the reduction in ethane emissions 

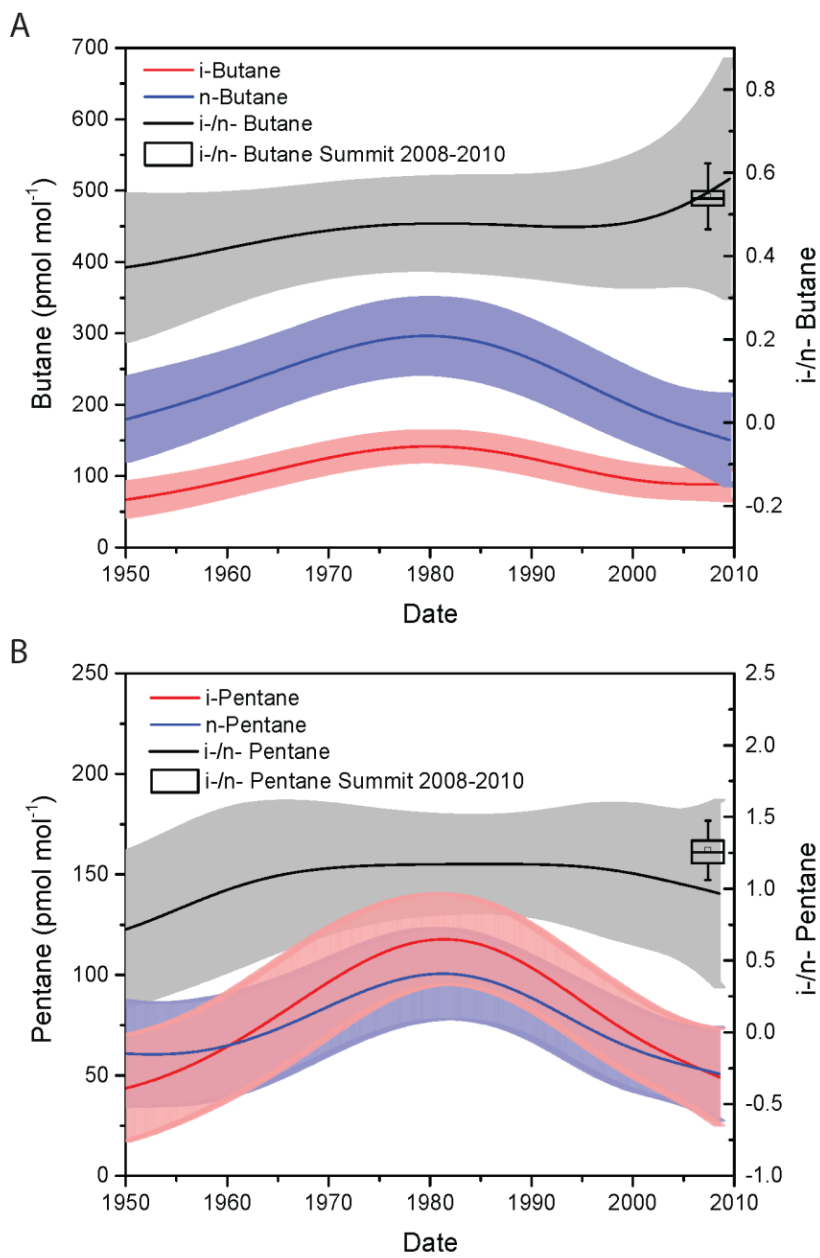

Fig. 10. Reconstructed NMHC histories based on the NEEM firn air data for the isomeric butane (A) and pentane pairs (B), with shaded areas indicating the 2- $\sigma$ uncertainty envelopes. Also included in this graph are whisker plots showing the statistical distribution of the isomer ratios (from $\sim 2600$ individual measurements) determined for butane and pentane from the in situ NMHC measurements conducted at Summit during 2008-2010.

was accompanied by a drop in methane emissions by $15-$ $30 \mathrm{Tg} \mathrm{yr}^{-1}$ (Aydin et al., 2011) and $10-21 \mathrm{Tg} \mathrm{yr}^{-1}$ (Simpson et al., 2012), respectively, and that these emission reductions have contributed to the observed decline in the atmospheric methane growth rate seen in the late 1990s to the first few years of the new millennium. These estimates of the cutback in ethane emissions offer an opportunity to estimate changes in $\mathrm{C}_{3}-\mathrm{C}_{5}$ NMHC fluxes by scaling those to ethane. The relative ratios of these NMHC in the firn data are not very useful for this purpose, as NMHC get oxidized at different rates during atmospheric transport, resulting in a decline in the $\mathrm{NMHC}_{i}$ / ethane ratio and lower values of these ratios at a downwind site. Alternatively, here we explore using urban ambient air data as a surrogate for estimating NMHC emission ratios. The extensive data reviewed
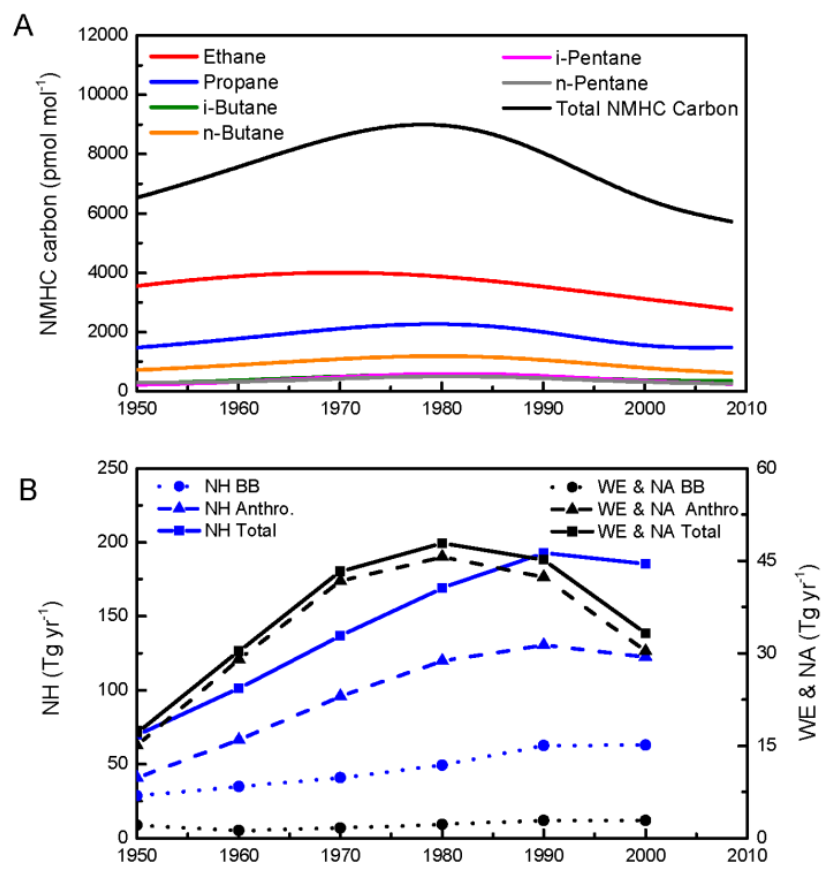

Fig. 11. Comparison of reconstructed histories of individual NMHC species and total $\mathrm{C}_{2}-\mathrm{C}_{5}$ NMHC carbon represented by these gases (top) with Northern Hemisphere (NH) VOC emission estimates, speciated by biomass burning (BB) and anthropogenic emissions (bottom) pooled together for all $\mathrm{NH}$ regions (blue data, left $y$ axis scale) and for the combination of North America (US, Canada) and Western Europe (black data, right $y$ axis scale).

by Warnecke et al. (2012) covering 2001-2008 yields average $\mathrm{NMHC}_{i} /$ ethane ratios for Los Angeles air of 0.68 , $0.15,0.28,0.34$ and 0.13 for propane, $i$-butane, $n$-butane, $i$ pentane, and $n$-pentane, respectively. These ratios are probably high estimates, as ethane sources within the LA Basin (mostly natural gas) are likely to be underrepresented compared to emission sources for higher NMHC. On the other hand, our findings show that $\mathrm{C}_{3}-\mathrm{C}_{5}$ have declined at significantly higher rates than ethane over the past 30-40 yr. Applying the LA-derived scaling factors to the $\sim 6 \mathrm{Tg} \mathrm{yr}^{-1}$ reduction in estimated fossil fuel ethane emissions (Aydin et al., 2011) would yield reductions of $\sim 6.2,1.9,3.5,5.2$, and $1.9 \mathrm{Tg} \mathrm{yr}^{-1}$ in fossil fuel emissions of propane, $i$-butane, $n$-butane, $i$-pentane, and $n$-pentane, respectively, or a combined $\sim 25 \mathrm{Tg} \mathrm{yr}^{-1}$ of $\mathrm{C}_{2}-\mathrm{C}_{5}$ NMHC emissions. This is likely a low estimate given, as mentioned above, the higher $\mathrm{NMHC}_{i}$ / ethane ratios in the 1970-1980s. Also, this emission reduction primarily represents the North America and Western Europe regions, and is likely offset to a substantial degree by the increase in emissions from Asia.

\subsection{NMHC-CO relationship}

Historic CO mole fractions were determined in parallel with the NMHC measurements. An in-depth presentation 
Table 3. Average decline rate of atmospheric NMHC from the firn air data reconstruction averaged over years 1985-2000 in comparison with the mean of the NMHC trend seen in the 2006-2011 Arctic site flask network data (mean of individual slopes determined for five sites $\pm 1-\sigma$ standard deviation of the mean). The last three columns list comparison data from three other recent NMHC trend determinations.

\begin{tabular}{|c|c|c|c|c|c|c|c|c|}
\hline & \multicolumn{3}{|c|}{ 1985-2000 reconstruction } & \multicolumn{2}{|c|}{ 2006-2011 ambient } & \multirow{2}{*}{$\begin{array}{r}\text { Aydin et al. } \\
(2011)^{\mathrm{a}} \\
\mathrm{pmol} \mathrm{mol}^{-1} \\
\mathrm{yr}^{-1}\end{array}$} & \multirow{2}{*}{$\begin{array}{r}\text { Simpson et al. } \\
(2012)^{\mathrm{b}} \\
\mathrm{pmol} \mathrm{mol}^{-1} \\
\mathrm{yr}^{-1}\end{array}$} & \multirow{2}{*}{$\begin{array}{r}\text { Worton et al. } \\
(2012)^{\mathrm{c}}\end{array}$} \\
\hline & $\max ($ year) & $\begin{array}{r}\mathrm{pmol} \mathrm{mol}^{-1} \\
\mathrm{yr}^{-1}\end{array}$ & $\begin{array}{r}\% \text { of } \max \\
\mathrm{yr}^{-1}\end{array}$ & $\begin{array}{r}\mathrm{pmol} \mathrm{mol}^{-1} \\
\mathrm{yr}^{-1}\end{array}$ & $\begin{array}{r}\% \text { of } \max \\
\mathrm{yr}^{-1}\end{array}$ & & & \\
\hline Ethane & 2000 (1979) & -20 & 1.0 & $-34( \pm 11)$ & $1.7( \pm 0.6)$ & -25 & $-12.4( \pm 1.3)$ & -47 \\
\hline Propane & 764 (1980) & -17 & 2.2 & $-8.2( \pm 7.8)$ & $1.1( \pm 1.0)$ & & & -17 \\
\hline$i$-Butane & $142(1980)$ & -2.9 & 2.0 & $-2.5( \pm 2.4)$ & $1.8( \pm 1.7)$ & & & -3.8 \\
\hline$n$-Butane & 296 (1980) & -6.3 & 2.1 & $-6.7( \pm 2.9)$ & $2.3( \pm 1.0)$ & & & -8.0 \\
\hline$i$-Pentane & 118 (1981) & -3.2 & 2.7 & $-5.8( \pm 1.3)$ & $4.9( \pm 1.1)$ & & & -3.1 \\
\hline$n$-Pentane & $101(1981)$ & -2.5 & 2.5 & $-1.6( \pm 1.5)$ & $1.6( \pm 1.5)$ & & & -2.8 \\
\hline
\end{tabular}

${ }^{\mathrm{a}} 1980-2000 ;{ }^{\mathrm{b}} 1984-2010 ;{ }^{\mathrm{c}} 1985-2000$, rates deduced from the graphs in Fig. 2 in Worton et al. (2012).

of the NEEM CO data and interpretation can be found in Petrenko et al. (2013). Here, we compare the reconstructed histories of $\mathrm{CO}$ and ethane from the NEEM firn air analyses. Because Northern Hemispheric CO is also associated primarily with anthropogenic emissions, particularly from combustion sources, correlations of $\mathrm{CO}$ with NMHC can provide a useful indicator of anthropogenically emitted hydrocarbons. Additionally, the $\mathrm{OH}$ radical is the major sink for both compound classes and $\mathrm{CO}$ and ethane are oxidized at rates that are less than a factor of two different: $k_{\mathrm{OH}+\text { ethane }}=2.4 \times 10^{-13} \mathrm{~cm}^{3}$ molecule ${ }^{-1} \mathrm{~s}^{-1} \quad$ (Atkinson, 2003 ) $k_{\mathrm{OH}+\mathrm{CO}}=1.44 \times 10^{-13} \mathrm{~cm}^{3}$ molecule ${ }^{-1} \mathrm{~s}^{-1}$ (Atkinson et al., 2004). A comparison of the $\mathrm{CO}$ and NMHC depth profiles shows similar behavior at depth, as well as similar seasonality. Notably, both compound classes show distinct maxima at $\sim 70-72 \mathrm{~m}$ depth of the profile. In the comparison of the $\mathrm{CO}$ and ethane depth profiles it must be considered that the diffusivity coefficients for ethane and $\mathrm{CO}$ are different by a factor of 1.35 , with $\mathrm{CO}$ being the faster diffusing molecule. Consequently, the $\mathrm{CO}$ at a given depth will have a slightly younger age distribution than ethane. Figure 12 illustrates the comparison of reconstructed trends of both species from the NEEM data. Here it can be seen that there is a similar trend between ethane and $\mathrm{CO}$, corroborating their emission from common sources. Ethane peaks earlier than $\mathrm{CO}$, with ethane reaching a maximum around 1970, while CO shows a broader maximum approximately $10 \mathrm{yr}$ later. Furthermore, ethane shows a faster decrease than does $\mathrm{CO}$. The increase in ethane mole fractions corresponds to a period of rapidly increasing natural gas production in the United States, with a local maximum around 1970. While the more recent decline in $\mathrm{CO}$ suggests decreased emissions from fossil fuel combustion, the faster declines in atmospheric concentrations of ethane relative to $\mathrm{CO}$ determined from the firn analysis may reflect reductions in ethane emissions through further emission controls in natural gas production and transport technology.

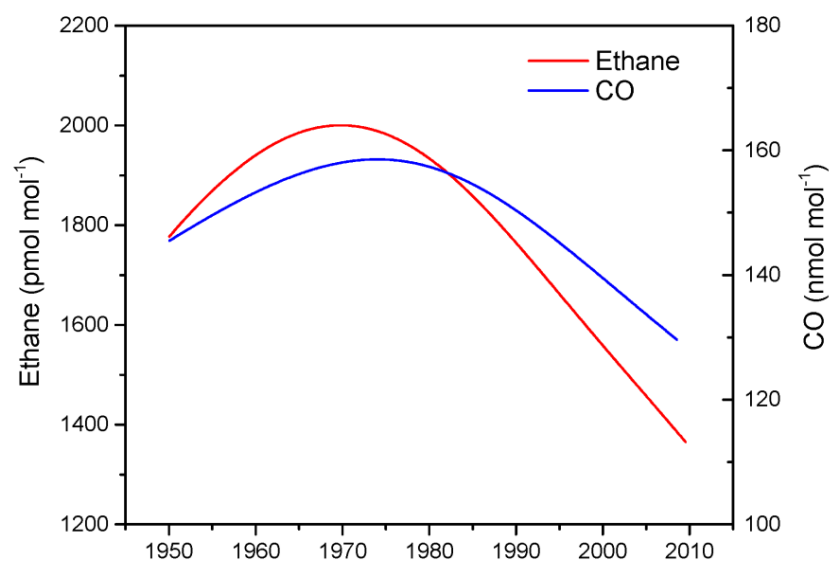

Fig. 12. Comparison of reconstructed histories of ethane and carbon monoxide from the NEEM firn air analyses. Please note that the $y$ axes scales were chosen such that bot gases have the same starting point, with relative scales for both species being the same in order to allow comparison of the relative mole fraction changes for both species.

\section{Conclusions}

The $\mathrm{C}_{2}-\mathrm{C}_{5}$ NMHC mole fraction depth profiles in firn air sampled from three $\sim 80 \mathrm{~m}$-deep boreholes retrieved at NEEM showed very similar profiles, illustrating the robustness of the firn air borehole extraction and analytical processing of air samples. The good agreement of firn air NMHC measurements between NEEM and NGRIP sites argues strongly for good preservation of these species in the firn.

All NMHC showed mole fraction maxima in the lock-in zone, with lower levels in the firn below and above, indicative of a maximum in atmospheric NMHC mole fractions in the recent past. The NEEM simulated NMHC histories were compared with results from two other previously published firn air borehole retrievals from other Greenland sites and 
with data from one ambient air-monitoring program. Overall good agreement between these independent studies was observed, confirming the validity of the NMHC histories reported in these studies. Consequently, firn air measurements and reconstruction of NMHC histories using firn air diffusion models are a robust method for reconstructing atmospheric mole fractions and emission trends of these compounds.

All NMHC show significant increases from the 1940s to $\sim 1970-1980$ and a trend reversal afterwards. These results agree with other recent trend analyses (Aydin et al., 2011; Simpson et al., 2012; Worton et al., 2012) that showed a peak in the atmospheric ethane mole fraction between 1960 and 1970. Our work presented here, in agreement with the findings of Worton et al. (2012), shows that other $\mathrm{C}_{3}-\mathrm{C}_{5}$ NMHC are behaving in a similar manner, suggesting that reductions in fossil fuel emission, and to a lesser extent biomass burning, similarly resulted in reduced atmospheric mole fractions of these NMHC.

Ethane deviates from the $\mathrm{C}_{3}-\mathrm{C}_{5} \mathrm{NMHC}$, peaking $\sim 10 \mathrm{yr}$ earlier. Ethane also precedes the peak seen in $\mathrm{CO}$ by a similar number of years. There is a correlation seen in the trends of the $\mathrm{C}_{3}-\mathrm{C}_{5}$ NMHC and CO (Petrenko et al., 2013), suggesting that emission reductions that have been implemented since the 1970s had the effect of reducing both $\mathrm{CO}$ and the $\mathrm{C}_{3}-\mathrm{C}_{5}$ NMHC. However, the \% increase and subsequent decline in the NMHC were larger than for $\mathrm{CO}$, reflecting the fact that emissions of $\mathrm{CO}$ and the $\mathrm{C}_{3}-\mathrm{C}_{5}$ NMHC are not completely coupled. The earlier decline in atmospheric ethane possibly reflects the fact that ethane release from natural gas producing practices such as venting, flaring, or fugitive emissions was cut back earlier than the onset of VOC emissions controls in the automobile sector that would have affected the higher molecular weight VOC to a larger degree.

The analyses presented here provide the first indication of a historic change in the isomeric ratios of the butane and pentane isomers, pointing towards changes in their source region emission ratios or their atmospheric processing. The trends seen in the earlier part of the record for isomeric butane and pentane ratios are in accordance with a relative increase in oxidation by $\mathrm{Cl}$ radicals. This observation is of quite some interest as it adds new supporting material to the hypotheses by Aydin et al. (2011) that 1980-2000 changes in the ethane/methane ratios might be due to a relative increase in the ethane oxidation rate from $\mathrm{Cl}$ radical chemistry.

Comparing the NMHC firn air reconstructed histories with regionally differentiated emission inventories showed that the Greenland records correlate more tightly with North American and Western European emissions than with total $\mathrm{NH}$ emissions. This image is confirmed by the comparison of ethane trends seen in the Greenland firn air vs. in ambient air in the North Pacific. These findings suggest that short-lived species such as NMHC, emissions from North America and Western Europe exhibit a stronger influence on Greenland firn air and ice core records than emissions from other $\mathrm{NH}$ regions. Histories of trace gases with relatively short atmo- spheric lifetimes on the scale of these NMHC ( $<2$ months) are thus more likely a reflection of the emission changes from these regions, and do not necessarily reflect the $\mathrm{NH}$ average trend.

\section{Supplementary material related to this article is available online at http://www.atmos-chem-phys.net/14/ 1463/2014/acp-14-1463-2014-supplement.pdf.}

Acknowledgements. We thank A. Hollister, CU Boulder, and K. Masarie, NOAA-ESRL, for processing of NOAA/INSTAAR network flask data and J. F. Lamarque, NCAR, for providing the VOC emission estimates data. E. Atlas, Rosenstiel School of Marine and Atmospheric Science, University of Miami, and D. Worton, University of California (formerly at the University of East Anglia), provided comparative NHMC and CFC measurements from NGRIP firn air. We thank the NEEM team, CPS Polar Services, and the 109th Air National Guard for field logistical support. This project was supported by the NOAA Postdoctoral Fellowship in Climate and Global Change (Petrenko) and US NSF awards 0632222 and 0806387 (White). NEEM is directed and organized by the Center of Ice and Climate at the Niels Bohr Institute and US NSF, Office of Polar Programs. It is supported by funding agencies and institutions in Belgium (FNRS-CFB and FWO), Canada (NRCan/GSC), China (CAS), Denmark (FIST), France (IPEV, CNRS/INSU, CEA and ANR), Germany (AWI), Iceland (RannIs), Japan (NIPR), Korea (KOPRI), the Netherlands (NWO/ALW), Sweden (VR), Switzerland (SNF), the United Kingdom (NERC) and the USA (US NSF, Office of Polar Programs). The in situ NMHC monitoring at Summit was supported by NASA grant NNX07AR26G (Helmig) and NSF grant ARC-0713943 (Helmig). The measurements at Utrecht University were funded by the Dutch National Science Foundation (NWO), grant number 016.071.605.

Edited by: R. van de Wal

\section{References}

Ambrose, D. and Tsonopoulos, C.: Vapor-liquid critical properties of elements and compounds. 2. Normal-alkanes, J. Chem. Eng. Data, 40, 531-546, doi:10.1021/je00019a001, 1995.

Andreae, M. O. and Merlet, P.: Emission of trace gases and aerosols from biomass burning, Global Biogeochem. Cy., 15, 955-966, 2001.

Atkinson, R.: Kinetics of the gas-phase reactions of $\mathrm{OH}$ radicals with alkanes and cycloalkanes, Atmos. Chem. Phys., 3, $2233-$ 2307, doi:10.5194/acp-3-2233-2003, 2003.

Atkinson, R., Baulch, D. L., Cox, R. A., Crowley, J. N., Hampson, R. F., Hynes, R. G., Jenkin, M. E., Rossi, M. J., and Troe, J.: Evaluated kinetic and photochemical data for atmospheric chemistry: Volume $\mathrm{I}-$ gas phase reactions of $\mathrm{O}_{\mathrm{x}}, \mathrm{HO}_{\mathrm{x}}, \mathrm{NO}_{\mathrm{x}}$ and $\mathrm{SO}_{\mathrm{x}}$ species, Atmos. Chem. Phys., 4, 1461-1738, doi:10.5194/acp-41461-2004, 2004. 
Aydin, M., Williams, M. B., and Saltzman, E. S.: Feasibility of reconstructing paleoatmospheric records of selected alkanes, methyl halides, and sulfur gases from Greenland ice cores, J. Geophys. Res.-Atmos., 112, D07312, doi:10.1029/2006jd008027, 2007.

Aydin, M., Verhulst, K. R., Saltzman, E. S., Battle, M. O., Montzka, S. A., Blake, D. R., Tang, Q., and Prather, M. J.: Recent decreases in fossil-fuel emissions of ethane and methane derived from firn air, Nature, 476, 198-201, doi:10.1038/nature10352, 2011.

Baker, A. K., Slemr, F., and Brenninkmeijer, C. A. M.: Analysis of non-methane hydrocarbons in air samples collected aboard the CARIBIC passenger aircraft, Atmos. Meas. Tech., 3, 311-321, doi:10.5194/amt-3-311-2010, 2010.

Battle, M., Bender, M., Sowers, T., Tans, P. P., Butler, J. H., Elkins, J. W., Ellis, J. T., Conway, T., Zhang, N., Lang, P., and Clarke, A. D.: Atmospheric gas concentrations over the past century measured in air from firn at the South Pole, Nature, 383, 231-235, doi:10.1038/383231a0, 1996.

Broadgate, W. J., Liss, P. S., and Penkett, S. A.: Seasonal emissions of isoprene and other reactive hydrocarbon gases from the ocean, Geophys. Res. Lett., 24, 2675-2678, doi:10.1029/97g102736, 1997.

Buizert, C., Martinerie, P., Petrenko, V. V., Severinghaus, J. P., Trudinger, C. M., Witrant, E., Rosen, J. L., Orsi, A. J., Rubino, M., Etheridge, D. M., Steele, L. P., Hogan, C., Laube, J. C., Sturges, W. T., Levchenko, V. A., Smith, A. M., Levin, I., Conway, T. J., Dlugokencky, E. J., Lang, P. M., Kawamura, K., Jenk, T. M., White, J. W. C., Sowers, T., Schwander, J., and Blunier, T.: Gas transport in firn: multiple-tracer characterisation and model intercomparison for NEEM, Northern Greenland, Atmos. Chem. Phys., 12, 4259-4277, doi:10.5194/acp-12-4259-2012, 2012.

Carpenter, L. J., Monks, P. S., Bandy, B. J., Penkett, S. A., Galbally, I. E., and Meyer, C. P.: A study of peroxy radicals and ozone photochemistry at coastal sites in the northern and southern hemispheres, J. Geophys. Res.-Atmos., 102, 25417-25427, doi:10.1029/97jd02242, 1997.

Chen, N. H. and Othmer, D. F.: New generalized equation for gas diffusion coefficient, J. Chem. Eng. Data, 7, 37-41, 1962.

Daubert, T. E.: Vapor-liquid critical properties of elements and compounds. 5. Branched alkanes and cycloalkanes, J. Chem. Eng. Data, 41, 365-372, doi:10.1021/je9501548, 1996.

Eckhardt, S., Stohl, A., Beirle, S., Spichtinger, N., James, P., Forster, C., Junker, C., Wagner, T., Platt, U., and Jennings, S. G.: The North Atlantic Oscillation controls air pollution transport to the Arctic, Atmos. Chem. Phys., 3, 1769-1778, doi:10.5194/acp-31769-2003, 2003.

Ehhalt, D. H., Rudolph, J., Meixner, F., and Schmidt, U.: Measurements of selected $\mathrm{C}_{2}-\mathrm{C}_{5}$ hydrocarbons in the background troposphere - vertical and latitudinal variations, J. Atmos. Chem., 3, 29-52, doi:10.1007/bf00049367, 1985.

Etiope, G. and Ciccioli, P.: Earth's Degassing: A Missing Ethane and Propane Source, Science, 323, 478-478, doi:10.1126/science.1165904, 2009.

Gautrois, M., Brauers, T., Koppmann, R., Rohrer, F., Stein, O., and Rudolph, J.: Seasonal variability and trends of volatile organic compounds in the lower polar troposphere, J. Geophys. Res.Atmos., 108, 4393, doi:10.1029/2002jd002765, 2003.

Gilman, J. B., Burkhart, J. F., Lerner, B. M., Williams, E. J., Kuster, W. C., Goldan, P. D., Murphy, P. C., Warneke, C., Fowler, C.,
Montzka, S. A., Miller, B. R., Miller, L., Oltmans, S. J., Ryerson, T. B., Cooper, O. R., Stohl, A., and de Gouw, J. A.: Ozone variability and halogen oxidation within the Arctic and sub-Arctic springtime boundary layer, Atmos. Chem. Phys., 10, 10223-10236, doi:10.5194/acp-10-10223-2010, 2010.

Gilman, J. B., Lerner, B. M., Kuster, W. C., and de Gouw, J. A.: Source Signature of Volatile Organic Compounds from Oil and Natural Gas Operations in Northeastern Colorado, Environ. Sci. Technol., 47, 1297-1305, doi:10.1021/es304119a, 2013.

Graedel, T. E. and Keene, W. C.: Tropospheric budget of reactive chlorine, Global Biogeochem. Cy., 9, 47-77, doi:10.1029/94gb03103, 1995.

Helmig, D., Oltmans, S. J., Morse, T. O., and Dibb, J. E.: What is causing high ozone at Summit, Greenland?, Atmos. Environ., 41, 5031-5043, doi:10.1016/j.atmosenv.2006.05.084, 2007.

Helmig, D., Tanner, D. M., Honrath, R. E., Owen, R. C., and Parrish, D. D.: Nonmethane hydrocarbons at Pico Mountain, Azores: 1. Oxidation chemistry in the North Atlantic region, J. Geophys. Res.-Atmos., 113, D20S91, doi:10.1029/2007jd008930, 2008.

Helmig, D., Bottenheim, J., Galbally, I. E., Lewis, A., Milton, M. J. T., Penkett, S., Plass-Duelmer, C., Reimann , S., Tans, P., and Theil, S.: Volatile Organic Compounds in the Global Atmosphere, Eos Trans. AGU, 90, 2009.

Helmig, D., Stephens, C., Carmore, J., and Hueber, J.: Seasonal cycle of non-methane hydrocarbons in the atmosphere and firn air at Summit, Greenland, Atmos. Environ., 85, 234-246, 2014.

Jobson, B. T., Niki, H., Yokouchi, Y., Bottenheim, J., Hopper, F., and Leaitch, R.: Measurements of C2-C6 hydrocarbons during the polar sunrise 1992 experiment - evidence of $\mathrm{Cl}$ atom and Br atom chemistry, J. Geophys. Res.-Atmos., 99, 25355-25368, 1994.

Kahl, J. D. W., Martinez, D. A., Kuhns, H., Davidson, C. I., Jaffrezo, J. L., and Harris, J. M.: Air mass trajectories to Summit, Greenland: A 44-year climatology and some episodic events, J. Geophys. Res.-Oceans, 102, 26861-26875, doi:10.1029/97jc00296, 1997.

Kleinman, L., Lee, Y. N., Springston, S. R., Lee, J. H., Nunnermacker, L., Weinsteinlloyd, J., Zhou, X. L., and Newman, L.: Peroxy radical concentration and ozone formation rate at a rural site in the southeastern united-states, J. Geophys. Res.-Atmos., 100, 7263-7273, doi:10.1029/95jd00215, 1995.

Klonecki, A., Hess, P., Emmons, L., Smith, L., Orlando, J., and Blake, D.: Seasonal changes in the transport of pollutants into the Arctic troposphere-model study, J. Geophys. Res.-Atmos., 108, 8367, doi:10.1029/2002jd002199, 2003.

Lamarque, J. F., Hess, P., Emmons, L., Buja, L., Washington, W., and Granier, C.: Tropospheric ozone evolution between 1890 and 1990, J. Geophys. Res.-Atmos., 110, D08304, doi:10.1029/2004JD005537, 2005.

Lamarque, J.-F., Bond, T. C., Eyring, V., Granier, C., Heil, A., Klimont, Z., Lee, D., Liousse, C., Mieville, A., Owen, B., Schultz, M. G., Shindell, D., Smith, S. J., Stehfest, E., Van Aardenne, J., Cooper, O. R., Kainuma, M., Mahowald, N., McConnell, J. R., Naik, V., Riahi, K., and van Vuuren, D. P.: Historical (1850-2000) gridded anthropogenic and biomass burning emissions of reactive gases and aerosols: methodology and application, Atmos. Chem. Phys., 10, 7017-7039, doi:10.5194/acp10-7017-2010, 2010. 
Lewis, A. C., Carpenter, L. J., and Pilling, M. J.: Nonmethane hydrocarbons in Southern Ocean boundary layer air, J. Geophys. Res.-Atmos., 106, 4987-4994, doi:10.1029/2000jd900634, 2001.

Lukas, M. A.: Strong robust generalized cross-validation for choosing the regularization parameter, Inverse Probl., 24, 034006, doi:10.1088/0266-5611/24/3/034006, 2008.

Mahieu, E., Duchatelet, P., Zander, R., Demoulin, P., Servais, C., Rinsland, C. P., Chipperfield, M. P., and De Maziere, M.: The evolution of inorganic chlorine above the Jungfraujoch station: an update, Proceedings of the 20th Quadrennial Ozone Symposium, 2, 997-998, 2004.

Masarie, K. A. and Tans, P. P.: Extension and integration of atmospheric carbon dioxide data into a globally consistent measurement record, J. Geophys. Res. 100, 11593-11610, 1995.

Mielke, L. H., Furgeson, A., and Osthoff, H. D.: Observation of $\mathrm{CINO}_{2}$ in a Mid-Continental Urban Environment, Environ. Sci. Technol., 45, 8889-8896, doi:10.1021/es201955u, 2011.

Montzka, S. A., Spivakovsky, C. M., Butler, J. H., Elkins, J. W., Lock, L. T., and Mondeel, D. J.: New observational constraints for atmospheric hydroxyl on global and hemispheric scales, Science, 288, 500-503, doi:10.1126/science.288.5465.500, 2000.

Montzka, S. A., Krol, M., Dlugokencky, E., Hall, B., Jockel, P., and Lelieveld, J.: Small Interannual Variability of Global Atmospheric Hydroxyl, Science, 331, 67-69, doi:10.1126/science.1197640, 2011.

Ohara, T., Akimoto, H., Kurokawa, J., Horii, N., Yamaji, K., Yan, X., and Hayasaka, T.: An Asian emission inventory of anthropogenic emission sources for the period 1980-2020, Atmos. Chem. Phys., 7, 4419-4444, doi:10.5194/acp-7-4419-2007, 2007.

Parrish, D. D., Hahn, C. J., Williams, E. J., Norton, R. B., Fehsenfeld, F. C., Singh, H. B., Shetter, J. D., Gandrud, B. W., and Ridley, B. A.: Indications of photochemical histories of pacific air masses from measurements of atmospheric trace species at point arena, california, J. Geophys. Res.-Atmos., 97, 15883-15901, 1992.

Parrish, D. D., Trainer, M., Young, V., Goldan, P. D., Kuster, W. C., Jobson, B. T., Fehsenfeld, F. C., Lonneman, W. A., Zika, R. D., Farmer, C. T., Riemer, D. D., and Rodgers, M. O.: Internal consistency tests for evaluation of measurements of anthropogenic hydrocarbons in the troposphere, J. Geophys. Res.-Atmos., 103, 22339-22359, doi:10.1029/98jd01364, 1998.

Petrenko, V. V., Martinerie, P., Novelli, P., Etheridge, D. M., Levin, I., Wang, Z., Blunier, T., Chappellaz, J., Kaiser, J., Lang, P., Steele, L. P., Hammer, S., Mak, J., Langenfelds, R. L., Schwander, J., Severinghaus, J. P., Witrant, E., Petron, G., Battle, M. O., Forster, G., Sturges, W. T., Lamarque, J.-F., Steffen, K., and White, J. W. C.: A 60 yr record of atmospheric carbon monoxide reconstructed from Greenland firn air, Atmos. Chem. Phys., 13, 7567-7585, doi:10.5194/acp-13-7567-2013, 2013.

Pollmann, J., Helmig, D., Hueber, J., Plass-Dülmer, C., and Tans, P.: Sampling, storage, and analysis of C2-C7 non-methane hydrocarbons from the US National Oceanic and Atmospheric Administration Cooperative Air Sampling Network glass flasks, J. Chromatogr. A, 1188, 75-87, 2008.

Pozzer, A., Pollmann, J., Taraborrelli, D., Jöckel, P., Helmig, D., Tans, P., Hueber, J., and Lelieveld, J.: Observed and simulated global distribution and budget of atmospheric $\mathrm{C}_{2}-\mathrm{C}_{5}$ alkanes,
Atmos. Chem. Phys., 10, 4403-4422, doi:10.5194/acp-10-44032010, 2010.

Prinn, R. G., Cunnold, D., Simmonds, P., Alyea, F., Boldi, R., Crawford, A., Fraser, P., Gutzler, D., Hartley D., Rosen, R., and Rasmussen, R.: Global average concentration and trend for hydroxyl radicals deduced from ALE/GAGE trichloroethane (methyl chloroform) data for 1978-1990, J. Geophys. Res., 97, 2445-2461, 1992.

Prinn, R. G., Huang, J., Weiss, R. F., Cunnold, D. M., Fraser, P. J., Simmonds, P. G., McCulloch, A., Harth, C., Reimann, S., Salameh, P., O’Doherty, S., Wang, R. H. J., Porter, L. W., Miller, B. R., and Krummel, P. B.: Evidence for variability of atmospheric hydroxyl radicals over the past quarter century, Geophys. Res. Lett., 32, L07809, doi:10.1029/2004g1022228, 2005.

Rasmussen, R. A. and Khalil, M. A. K.: Atmospheric trace gases trends and distributions over the last decade, Science, 232, 16231624, doi:10.1126/science.232.4758.1623, 1986.

Rommelaere, V., Arnaud, L., and Barnola, J. M.: Reconstructing recent atmospheric trace gas concentrations from polar firn and bubbly ice data by inverse methods, J. Geophys. Res.-Atmos., 102, 30069-30083, doi:10.1029/97jd02653, 1997.

Ross, S. M.: Peirce's criterion for the elimination of suspect experimental data, J. Eng. Technol., 20, 38-41, 2003.

Sapart, C. J., Martinerie, P., Witrant, E., Chappellaz, J., van de Wal, R. S. W., Sperlich, P., van der Veen, C., Bernard, S., Sturges, W. T., Blunier, T., Schwander, J., Etheridge, D., and Röckmann, T.: Can the carbon isotopic composition of methane be reconstructed from multi-site firn air measurements?, Atmos. Chem. Phys., 13, 6993-7005, doi:10.5194/acp-13-6993-2013, 2013.

Schwander, J., Barnola, J. M., Andrie, C., Leuenberger, M., Ludin, A., Raynaud, D., and Stauffer, B.: The age of the air in the firn and the ice at summit, greenland, J. Geophys. Res.-Atmos., 98, 2831-2838, doi:10.1029/92jd02383, 1993.

Sillman, S., Logan, J. A., and Wofsy, S. C.: The sensitivity of ozone to nitrogen-oxides and hydrocarbons in regional ozone episodes, J. Geophys. Res.-Atmos., 95, 1837-1851, doi:10.1029/JD095iD02p01837, 1990.

Simpson, I. J., Andersen, M. P. S., Meinardi, S., Bruhweiler, L., Blake, N. J., Helmig, D., Rowland, F. S., and Blake, D. R.: Longterm decline of global atmospheric ethane concentrations and implications for methane, Nature, 488, 490-494, 2012.

Singh, H. B., Viezee, W., and Salas, L. J.: Measurements of selected $\mathrm{C}_{2}-\mathrm{C}_{5}$ hydrocarbons in the troposphere - latitudinal, vertical, and temporal variations, J. Geophys. Res.-Atmos., 93, 1586115878, doi:10.1029/JD093iD12p15861, 1988.

Stohl, A.: Characteristics of atmospheric transport into the Arctic troposphere, J. Geophys. Res.-Atmos., 111, D11306, doi:10.1029/2005jd006888, 2006.

Tanaka, P. L., Oldfield, S., Neece, J. D., Mullins, C. B., and Allen, D. T.: Anthropogenic sources of chlorine and ozone formation in urban atmospheres, Environ. Sci. Technol., 34, 4470-4473, doi:10.1021/es991380v, 2000.

Tanaka, P. L., Riemer, D. D., Chang, S. H., Yarwood, G., McDonald-Buller, E. C., Apel, E. C., Orlando, J. J., Silva, P. J., Jimenez, J. L., Canagaratna, M. R., Neece, J. D., Mullins, C. B., and Allen, D. T.: Direct evidence for chlorine-enhanced urban ozone formation in Houston, Texas, Atmos. Environ., 37, 1393 1400, doi:10.1016/s1352-2310(02)01007-5, 2003. 
Tanner, D., Helmig, D., Hueber, J., and Goldan, P.: Gas chromatography system for the automated, unattended, and cryogen-free monitoring of $\mathrm{C} 2$ to $\mathrm{C} 6$ non-methane hydrocarbons in the remote troposphere, J. Chromatogr. A, 1111, 76-88, 2006.

Thompson, C. R., Helmig, D., Park, J. H., and Hueber, J.: Evidence for radical oxidation of non-methane hydrocarbons within a continental seasonal snowpack, in preparation, 2014.

Thoning, K. W., Tans, P. P., and Komhyr, W. D.: Atmospheric carbon-dioxide at mauna loa observatory. 2. Analysis of the NOAA GMCC data, 1974-1985, J. Geophys. Res.-Atmos., 94, 8549-8565, doi:10.1029/JD094iD06p08549, 1989.

Thornton, J. A., Kercher, J. P., Riedel, T. P., Wagner, N. L., Cozic, J., Holloway, J. S., Dube, W. P., Wolfe, G. M., Quinn, P. K., Middlebrook, A. M., Alexander, B., and Brown, S. S.: A large atomic chlorine source inferred from mid-continental reactive nitrogen chemistry, Nature, 464, 271-274, doi:10.1038/nature08905, 2010.

von Schneidemesser, E., Monks, P. S., and Plass-Duelmer, C.: Global comparison of VOC and $\mathrm{CO}$ observations in urban areas, Atmos. Environ., 44, 5053-5064, doi:10.1016/j.atmosenv.2010.09.010, 2010.

Wang, Z., Chappellaz, J., Martinerie, P., Park, K., Petrenko, V., Witrant, E., Emmons, L. K., Blunier, T., Brenninkmeijer, C. A. M., and Mak, J. E.: The isotopic record of Northern Hemisphere atmospheric carbon monoxide since 1950: implications for the CO budget, Atmos. Chem. Phys., 12, 4365-4377, doi:10.5194/acp-12-4365-2012, 2012.

Warneke, C., de Gouw, J. A., Holloway, J. S., Peischl, J., Ryerson, T. B., Atlas, E., Blake, D., Trainer, M., and Parrish, D. D.: Multiyear trends in volatile organic compounds in Los Angeles, California: Five decades of decreasing emissions, J. Geophys. Res.-Atmos., 117, D00v17, doi:10.1029/2012jd017899, 2012.
Witrant, E. and Martinerie, P.: Input Estimation from Sparse Measurements in LPV Systems and Isotopic Ratios in Polar Firns, Proc. of the 5th IFAC Symposium on System Structure and Control, doi:10.3182/20130204-3-FR-2033.00201, 659-664, 2013.

Witrant, E., Martinerie, P., Hogan, C., Laube, J. C., Kawamura, K., Capron, E., Montzka, S. A., Dlugokencky, E. J., Etheridge, D., Blunier, T., and Sturges, W. T.: A new multi-gas constrained model of trace gas non-homogeneous transport in firn: evaluation and behaviour at eleven polar sites, Atmos. Chem. Phys., 12, 11465-11483, doi:10.5194/acp-12-11465-2012, 2012.

Worton, D. R., Sturges, W. T., Reeves, C. E., Newland, M. J., Penkett, S. A., Atlas, E., Stroud, V., Johnson, K., Schmidbauer, N., Solberg, S., Schwander, J., and Barnola, J.-M.: Evidence from firn air for recent decreases in non-methane hydrocarbons and a 20th century increase in nitrogen oxides in the northern hemisphere, Atmos. Environ., 54, 592-602, 2012.

Zuiderweg, A., Holzinger, R., and Röckmann, T.: Analytical system for stable carbon isotope measurements of low molecular weight $\left(\mathrm{C}_{2}-\mathrm{C}_{6}\right)$ hydrocarbons, Atmos. Meas. Tech., 4, 11611175, doi:10.5194/amt-4-1161-2011, 2011.

Zuiderweg, A., Holzinger, R., Martinerie, P., Schneider, R., Kaiser, J., Witrant, E., Etheridge, D., Petrenko, V., Blunier, T., and Röckmann, T.: Extreme ${ }^{13} \mathrm{C}$ depletion of $\mathrm{CCl}_{2} \mathrm{~F}_{2}$ in firn air samples from NEEM, Greenland, Atmos. Chem. Phys., 13, 599-609, doi:10.5194/acp-13-599-2013, 2013. 